\title{
Unconventional technologies available for phase change materials (PCM) characterization. Part 1. Thermophysical properties
}

\author{
Luisa F. Cabeza ${ }^{1}$, Camila Barreneche ${ }^{1,2}$, Ingrid Martorell ${ }^{1}$, Laia Miró ${ }^{1}$, Sana Sari-Bey ${ }^{3}$, Magali \\ Fois $^{3}$, Halime O. Paksoy ${ }^{4}$, Nurten Sahan ${ }^{4}$, Robert Weber ${ }^{5}$, Mariaella Constantinescu ${ }^{6}$, Elena \\ Maria Anghel $^{6}$, Marta Malikova ${ }^{7}$, Igor Krupa ${ }^{7}$, Mónica Delgado $^{8}$, Pablo Dolado ${ }^{8}$, Piotr
} Furmanski $^{9}$, Maciej Jaworski ${ }^{9}$, Thomas Haussmann ${ }^{10}$, Stefan Gschwander ${ }^{10}$, A. Inés Fernández ${ }^{2}$

${ }^{1}$ GREA Innovació Concurrent, Universitat de Lleida, Edifici CREA, Pere de Cabrera s/n, 25001-Lleida, Spain, Phone: +34-973 003576, e-mail: lcabeza@ diei.udl.cat

${ }^{2}$ Department of Materials Science \& Metallurgical Engineering, Universitat de Barcelona, Martí i Franqués 1-11, 08028-Barcelona, Spain, Phone: +34-934021298, e-mail: ana_inesfernandez@ub.edu

${ }^{3}$ CERTES EA 3481 - Centre d'Etude et de Recherche en Thermique, Environnement et Systèmes, Université Paris Est Créteil, 61 av. du Général de Gaulle, 94010 Créteil cedex, France, Phone: +33.1.45.17.18.44, e-mail : fois@u-pec.fr

${ }^{4}$ Department of Chemistry, Çukurova University, Turkey, Phone: +90-3223386418, e-mail: hopaksoy@cu.edu.tr

${ }^{5}$ EMPA, Building Science and Technology Laboratory, Uberlandstrasse 129, 8600 Dubendorf, Switzerland, Phone: +41 5876543 38, e-mail: robert.weber@empa.ch

${ }^{6}$ Institute of Physical Chemistry "Ilie Murgulescu" of Romanian Academy, Spl. Independentei 202, 060021 Bucharest, Romania, Phone: +40 (004) 0213188595 e-mail: mariella_const@yahoo.com

${ }^{7}$ Polymer Institute, Slovak Academy of Sciences, Dubravska cesta 9, 84545 Bratislava, Slovakia, Phone: +421 23229 4334, e-mail: igor.krupa@savba.sk

${ }^{8}$ Aragón Institute for Engineering Research (I3A), Thermal Engineering and Energy Systems Group, University of Zaragoza, Agustín Betancourt Building, C/María de Luna 3, 50018 Zaragoza, Spain, Phone: +34- 976761000 ext5258, e-mail: monica.delgado@unizar.es ${ }^{9}$ Institute of Heat Engineering, Warsaw University of Technology, Nowowiejska 21-25, 00-665 Warsaw, Poland, Phone: +48 2223452 09, e-mail: maciej.jaworski@itc.pw.edu.pl

${ }^{10}$ Fraunhofer Institute for Solar Energy Systems,Heidenhofstrasse 2, 79110 Freiburg, Germany, Phone: +49- 7614588 5351, e-mail:thomas.haussmann@ise.fraunhofer.de 


\begin{abstract}
The use of thermal energy storage by phase change materials (PCM) is increasing in interest for building applications. For the deployment of the technology, appropriate characterization of PCM and hybrid PCM is essential, but it is not always possible to carry it out with conventional equipment, mainly due to the sample size. This paper shows equipment developed in different research centers and universities to analyze thermophysical properties, such as specific heat, latent heat and melting temperature, and thermal conductivity and diffusivity of PCM and hybrid PCM materials.
\end{abstract}

Keywords: Phase change materials (PCM), characterization, thermophysical properties

\title{
1. Introduction
}

The use of storage in a building can smooth temperature fluctuation. Thermal energy storage in buildings can be implemented by sensible heat (increasing and decreasing the temperature of the building envelopes, for example), by latent heat (with the inclusion of phase change materials PCM - to increase thermal inertia) or with thermochemical heat (with the use of chemical reactions or sorption systems).

The main advantage of latent heat storage is the high storage density in small temperature intervals. Latent storage can be used for heating and for cooling of buildings, and it can be incorporated as a passive system or also in active systems. A lot of information on materials and their application in buildings can be found in recently published reviews [1-7].

Polymers and expanded graphite are described as matrix for hybrid PCM composites with the main objective of shape stabilization or encapsulation of the material when is liquid. Studies report samples sizes from about several $\mathrm{mm}$ to few $\mathrm{cm}$ which is further called bulk scale. Other non-technical ceramic materials such as concrete or gypsum have been used to macroencapsulate PCM for building applications. The PCM used were either microencapsulated commercial paraffin, or without microencapsulation by incorporating the paraffin with impregnation, giving also hybrid materials.

Thermophysical properties are those which give information about the amount of energy that such materials and composites can store. But the characterization of thermophysical properties is not always easy and for composites many times cannot be carried out with conventional laboratory equipment, mostly due to the sample size. 
In 2004 several German PCM-companies founded the "RAL Gütegemeinschaft PCM e.V", an association with the aim to define and survey quality criteria for PCM, especially in construction materials. In the last few years some other European companies joined the RAL group. Fraunhofer ISE and ZAE Bayern were commissioned to define these quality criteria and useful measuring methods for testing. The RAL quality standard is focused on PCM-Materials itself and PCM compounds e.g. for encapsulation. But also objects and systems containing PCM can be tested. Since 2008 the label RAL Gütezeichen 896 is approved by RAL and can be awarded to products.

This paper presents available characterization equipment and methods of characterization of thermophysical properties of PCM and hybrid phase change materials, with special attention to home-made equipment and own developed methodologies. Commercial equipment is presented when it is used in non-conventional characterization analysis. The paper includes analysis of thermophysical properties like thermal conductivity and thermal diffusivity, other properties will be covered in a second paper [8]. Described characterization equipment and methods show capabilities for testing from nano-scale to macro-scale, including pilot plant scale.

\section{Substances to be used in the verification of the testing set-ups}

The thermophysical properties of PCM show particularities that make important to choose and adequate reference material for verification and calibration of the testing set-ups. This issue is not trivial and the increasing usage of PCM materials and products make quality assurance more and more important.

In standard thermal analysis methods are commonly designed to test pure substances which exhibit no subcooling and no temperature change during its solid-liquid phase change. Also, other testing facilities are partially modified for testing in solid and in liquid phase. Then the uncertainty of these measurements cannot be determined using solid reference materials, so other liquid reference should be found. That is the case when measuring thermal diffusivity using a Laser Flash device.

A compendium of reference substances that can be used for PCM testing will be desirable. Some substances have already been used are listed in Table 1. 


\section{Enthalpy-temperature curves}

\subsection{DSC}

One of the most important properties is the enthalpy-temperature relationship $\mathrm{h}(\mathrm{T})$. When this relationship is determined using conventional differential scanning calorimetry (DSC) with standard methods and procedures, results for PCM are often wrong. The enthalpy values from heating/cooling are systematically shifted to higher/lower temperatures. This temperature shift originates from a temperature gradient inside the PCM and depends on the heating/cooling rate and sample mass.

There are different possibilities to use a DSC in thermal analysis of PCM, but the most common used are the dynamic method and the step method [11].

The most widely used scanning mode consists of heating and cooling segments at constant rates (dynamic method). A typical temperature program and corresponding signal are shown in Figure 1.

The dynamic method is commonly used for the determination of melting enthalpies. For heat storage applications, the interesting value is the sum of both latent and sensible heat $h$. In this case, good sensitivity also for small signals is necessary. This is achieved using the heat flow rate calibration. For the determination of $h$, a dynamic program is executed three times:

- First, with the empty crucible to generate the baseline.

- Second, with a standard material (usually sapphire) in the same crucible to generate the standard line.

- Third, with the sample in the same crucible to generate the sample line.

From the heat flux, the specific heat as a function of temperature can be obtained with the DSC software using the baseline, the sapphire and the sample heat-flux signal and the enthalpy is determined by integration.

Another measurement routine is the step method. Here, the heating or cooling is not continuous, but small heating ramps are followed by periods in which the temperature is kept constant to allow the sample to reach thermal equilibrium. The resulting temperature program has small steps, and the signal created is a sequence of different peaks. A typical temperature program and resulting signal is shown in Figure 2. 
The size of the steps should be long enough to ensure thermal equilibrium in the sample. short, the signal will not fall back completely to the baseline and the thermal effect will be attributed to the following temperature interval. However, if this happens, it can be detected directly by reading the signal.

In the step method, the evaluation considers only peak areas and the exact shape of the baseline has no influence on the resulting $h(T)$ relationship. Therefore, we use the heat calibration for the evaluation of the data. The heat calibration is based on the comparison of measured peak areas of phase changes of standard materials to literature values of the phase change enthalpies. A sensitivity profile for the instrument is created and used to convert the directly measured thermovoltage signal into the heat-flux signal. This calibration only needs to be repeated from time to time, to assure the correct performance of the instrument.

From the sample heat-flux signal, the enthalpy $h(T)$ is determined by integration of every peak. While working with a DSC the resulting characteristic points are depending on heating rate, heat conductivity and sample mass. These influences get reduced by performing a heat-rate test. The heat rate test consists of several measurements on the same sample with different heating rates. At a certain heating rate the differences in the enthalpy temperature curve to the next one at doubled heating rate are so small, that the assumption of a measurement near to the thermal equilibrium becomes true. This allows separating material properties like subcooling from failures due to the measurement setup.

Additionally, RAL defined some regulations on how the enthalpie-temperature curve must be presented to customers. Both latent and sensible heat is taken into account. The stored and released energy is separated into $1 \mathrm{~K}$ temperature intervals. For each temperature interval, the stored energy is shown (Figure 3). Customers can clearly see which amount of energy can be stored in a certain temperature range and the influence of subcooling.

Stability of PCM materials is very important for the technical usage. RAL is only testing cyclic stability which is only a part of a full accelerated aging test. 6 classes are defined ranging from class $\mathrm{F}$ with more than 50 cycles up to class A with more than 10000 cycles. Apart from the temperature profile, RAL is defining the amount of control measurements during the cycling tests. Tests, especially for class A, can last very long. Therefore it is allowed to use the quality label after class $F$ is successfully tested. After the full completion of the cycle test, the certificate is granted. Cycling tests are not needed for every material. In some cases it is allowed 
to transfer tested results to similar products. The cycling test must be performed only during the initial certification process.

The main limitation of DSCt is the conditions the sample must fulfill: it should be small, pure, and homogeneous. This is a huge limitation because there are many samples that cannot achieve homogeneous conditions since they are a composite materials or a mixture of different components. A new building envelope material was developed by Barreneche et al. [12]. This material has the particularity of encapsulating a PCM in a polymeric matrix. The material was thermally analyzed by DSC using a conventional blank (empty crucible). Several limitations for PCM signal evaluation were observed (Figure 4).

A new methodology was designed based on subtracting different blanks to the composite material in order to improve the PCM signal (showing more accurate, acuter, clearer peaks of phase change) and reduce the matrix interferences in DSC analysis. The DSC signal is improved using these non-conventional blanks (Figure 5). The effect of the interference is significantly reduced. On the other hand, these interferences are due to the polymer matrix because the result does not change when the blank incorporates the filler (electrical arc furnace dust -EAFD).

\subsection{Twin Bath Method}

An apparatus was designed and constructed at Çukurova University (Turkey) to measure enthalpy-temperature curves $[13,14]$. Change of temperature and energy loads with time are measured, controlled and recorded for two baths using the apparatus shown in Figure 6. It consists of two well stirred identical baths with Techne TU-16A model thermoregulators. The type of working liquid in the baths varies depending on the operational requirements. Each bath is heated by an electrical resistance heater. Assuming that all the electrical energy delivered to the heating resistor is converted into heat, the energy load is controlled with the adjusted input voltage by a variac. The instantaneous voltage and electric currents are measured and recorded by a data logger in order to determine power inputs for the individual baths. To cool the baths to ambient temperature, identical finned copper coils with tap water circulating in them are used. For temperatures below ambient, additional heat pump systems may be used. Nine individually calibrated thermistors are used to measure the temperatures of the working liquids and heat storage material. The deviations in the power measurements are $1 \%$, while the temperatures are measured within an accuracy of $\pm 0.5^{\circ} \mathrm{C}$. The number of readings in the measurements is adjustable depending on the sample studied and are averaged to achieve a better accuracy. 
To calibrate the system, the baths are filled with the same amount of working liquids chosen. After that, the change of heat loads of baths and the temperatures of the working liquids with time are measured and recorded in order to test the baths, with the emphasis on identical behavior for the heating and cooling of the working liquids. After ensuring the identical operating behavior of the baths, two types of experiment can be carried out: in the first type, two baths are heated simultaneously at a constant rate over a fixed temperature interval, when one of the baths contains the sample and the other contains the working liquid alone.

Since both baths operate under similar conditions the heat loss to the surroundings $\mathrm{Q}_{\mathrm{L}}$ and the heat capacities of the working liquids $\mathrm{Q}_{\mathrm{B}}$ are the same and will cancel each other when the energy loads of the baths are compared according to:

$$
\begin{array}{ll}
\Delta Q=\left(Q_{B}+Q_{S}+Q_{C}+Q_{L}\right)_{b a t h, 1}-\left(Q_{B}+Q_{L}\right)_{b a t h, 2} & \text { Eq. } 1 \\
\Delta Q=Q_{B}+Q_{C} & \text { Eq. } 2
\end{array}
$$

where $\mathrm{Q}_{S}$ denotes the heat absorbed by the sample material and $\mathrm{Q}_{\mathrm{C}}$ is the heat capacity of the container. The value of $\mathrm{Q}_{\mathrm{S}}$ consists of heat capacities of solid and liquid phases as well as the heat of melting $H_{m}$ of the sample, which is given for a pure sample by:

$$
\begin{array}{ll}
\left.Q_{S}=M_{S}\left[C_{p, S}\left(T_{m}-T_{0}\right)\right]+H_{m}+C_{p, l}\left(T_{s}-T_{m}\right)\right] & \text { Eq. } 3 \\
\mathrm{Q}_{\mathrm{C}}=M_{C} \cdot C_{p, C}\left(T_{S}-T_{0}\right) & \text { Eq. } 4
\end{array}
$$

where $M_{S}$ is the mass, while $C_{p, S}$ and $C_{p, l}$ are the specific heats of solid and liquid states of the sample respectively. $T_{0}$ and $T_{S}$ are initial and final temperatures of the sample, and $T_{m}$ is the melting point of the sample. $M_{C}$ and $C_{p, C}$ are the mass and the specific heat of the container, respectively.

In order to determine the heat capacity and phase transition heat of the storage material, a reference material with an identical encapsulation may be used in the second bath, hence the value of $Q_{S}$ may be calculated from the comparison of the energy loads of the baths:

$$
\begin{array}{ll}
\Delta Q=\left(Q_{B}+Q_{S}+Q_{C}+Q_{L}\right)_{\text {bath }, 1}-\left(Q_{B}+Q_{R}+Q_{C}+Q_{L}\right)_{\text {bath }, 2} & \text { Eq. } 5 \\
Q_{S}=\Delta Q+Q_{R} & \text { Eq. } 6 \\
Q_{R}=M_{R} C_{p, R}\left(T_{S}-T_{0}\right) & \text { Eq. } 7
\end{array}
$$


where $M_{R}$ and $C_{p, R}$ are the mass and specific heat, respectively, of the reference material. Materials with known calorimetric properties may be used as the reference. For cooling, tap water and a heat pump may be used depending on the cooling level.

In the second type of experiment, the sample may be introduced into one of the preheated baths at the set temperature, when the other bath contains only the working liquid. Hence the compensation energy required by the bath with the sample may be measured and recorded until the set temperature of the baths will give the summation of heats absorbed by the sample and the container.

$$
\begin{array}{ll}
\Delta Q=\left(Q_{S}+Q_{C}+Q_{L}\right)_{b a t h, 1}-\left(Q_{L}\right)_{b a t h, 2} & \text { Eq. } 8 \\
\Delta Q=Q_{S}+Q_{C} & \text { Eq. } 9
\end{array}
$$

This type of differential measurement as well as the heating and cooling curves will supply valuable information on the thermal behavior of the heat storage material encapsulated in the required size and shape considering the economy and heat transfer characteristics of the actual system to be designed. The heating and cooling curves of $2.2 \mathrm{~kg}$ of paraffin in glass cylindrical containers are shown in Figure 7.

The total heat $\mathrm{Q}_{\mathrm{T}}$ stored by the encapsulated samples of paraffin may be measured by comparing the power loads of the baths obtained from both types of experiments explained above. The total heat consists of heat capacities of the sample in solid and liquid states as well as the heat capacity of the container. Figure shows the measurements from the second type of experiment. Total heat $\mathrm{Q}_{\mathrm{T}}$ measured is calculated from the area under the peak.

\subsection{T-History}

T-History method is based on an air enclosure where temperature is constant and two samples are introduced at a different temperature from the temperature in the air enclosure. During the heating or cooling process, three temperatures are registered, that of the ambient (air enclosure), and those of the two samples. The two samples are one reference substance whose thermal properties are known (frequently water) and one PCM whose thermal properties should be determined with the results of the test. At the University of Zaragoza (Spain), Marín et al. [15] made improvements in order to obtain enthalpy vs. temperature curves. They based their improvements on finite increments method. Other properties can be studied like subcooling and hysteresis analyzing the enthalpy-temperature curves. The set-up developed is seen in Figure 9. 
The main advantages of the T-history method compared to DSC or Adiabatic Calorimetry are:

- Precision in energy and temperature measurement.

- Sample mass and heating and cooling rate similar to application.

- Other properties can be studied like subcooling and hysteresis analysing the Enthalpy vs. Temperature curves.

Figure 10 shows an example of $\mathrm{h}$ vs. T curves obtained in a T-History installation. Detailed information about methodology of verification of a T-History installation proposed by University of Zaragoza in collaboration with ZAE Bayern is given by Lázaro et al. [16].

The schematic plan of the implementation of this technique at Empa (Switzerland) is shown in Figure 11 [17]. Here, the vessel has been made out of a glass and later of a polyethylene flask. The insulation of the flask is polyurethane foam (Figure 12). A polystyrene cup was used as an outer shell. The flask is sealed with a rubber cone, allowing leading a thermocouple sensor into the PCM sample. For the first test performed, the vessel was swimming in the bath, pressing against the insulation with which the bath has been covered. In future tests, the vessel shall be attached to the cover before the vessel is emerged into the water.

For calibration purposes an insulated vessel is filled with de-ionized water and then put into a water bath. The water bath is cycling between an upper $\left(40^{\circ} \mathrm{C}\right)$ und a lower $\left(5^{\circ} \mathrm{C}\right)$ temperature. Both temperatures, the one from the water bath and that of the vessel are measured. Knowing the mass and heat capacity of the water in the vessel, a heat transfer unit (HTU) for the vessel can be calculated (spread sheet calculation):

$$
H T U=u \cdot A=\frac{1}{\Delta t_{\text {timestep of measurement }}} \cdot \frac{m_{\mathrm{H}_{2} \mathrm{O}} \cdot c_{\mathrm{H}_{2} \mathrm{O}} \cdot\left(\vartheta_{\text {insidenew }}-\vartheta_{\text {inside,old }}\right)}{\vartheta_{\text {outsidenew }}-\vartheta_{\text {insidenew }}} \quad \text { Eq. } 10
$$

The HTU-value specifies the overall heat transfer rate through the shell of the vessel at a temperature difference of $1 \mathrm{~K}$ between inside and outside. This includes convection at the outside and heat transfer through the insulation.

Once the HTU-value is calculated, the measurements with PCM can be conducted and logged. The heat capacity of the PCM depending on the temperature can be assessed with the following relation: 
$c_{P C M}\left(\vartheta_{\text {inside }}\right)=\frac{1}{\Delta \vartheta_{\text {temperature class }}} \cdot \sum_{\text {temperature class }} \frac{H T U \cdot\left(\vartheta_{\text {outsidenew }}-\vartheta_{\text {insidenew }}\right) \cdot \Delta t_{\text {timestep of measurement }}}{m_{P C M}}$ Eq. 11

The measurements with the T- history method show the temperature curves given in Figure 13.

Updates of this methodology can be found in the review published by Solé et al. [18].

\subsection{T-t comparative curves}

University of Barcelona (Spain) has built a new equipment to evaluate the response of construction materials at macro scale $(300 \times 300 \times 300 \mathrm{~mm})$ containing PCM [19]. This equipment is a polyurethane shell having two cavities where are placed the sample and the reference. This sandwich configuration has a heating plate with a kanthal resistance (13 $\Omega$ ) in between. There are three temperature sensors (Pt-100) measuring each sample and another sensor is measuring the room temperature (see Figure 14 left).

The thermal experiments performed with this equipment were carried out starting at $31^{\circ} \mathrm{C}$. When the temperature is at steady state conditions, the heating plate is disconnected and the temperatures registered with the sensors located in the inner surface, the exterior surface and the center of the sample (Figure 14 right). The room temperature is controlled and has to be lower than the melting temperature of the PCM. Applying this method the evolution of the sample temperature vs. time is analyzed. The temperature difference between the reference and the sample under study shows the PCM thermal effect. The sample analyzed in the thermal response (Figure 14 right) is a gypsum matrix incorporating 15\% wt PCM.

\subsection{Panel test experimental set-up}

The panel test setup is used as a "small scale" version of a ceiling panel at Empa (Switzerland). With constant or controlled heat fluxes on the bottom side, the resulting temperature has been measured [17].

The construction of the box is schematically shown in Figure 15. The test setup consists of one (or two) heat exchanger, two heat flux sensors and the panel filled with PCM (Figure 16).

At Fraunhofer ISE (Germany) a plate test apparatus was developed to test construction materials with PCM in large scale samples $(50 \times 50 \mathrm{~cm}$ up to $30 \mathrm{~cm}$ thick) in different ways: 
- Heat transfer coefficient.

- Enthalpy temperature curve.

- Dynamic behaviour of a construction at various conditions.

When used in construction materials PCMs often behave different compared to pure materials. The plate apparatus is the needed link between small scale DSC and real scale test room measurements when developing PCM for building integration.

A scheme of the apparatus is shown in Figure 17. Heat or cold is applied to the sample with two copper plates. The copper plates get tempered by water thermostats or in a newer version of the apparatus with Peltier-Elements electrically. Between sample and copper plate temperature and heat flow sensors are installed in a thin epoxy resin layer. To ensure a one dimensional heatflow through the sample the whole apparatus is insulated to the ambient. Optional a fully controlled water circuit can be used for dynamic measurements of active cooled PCM-Systems e.g. chilled ceilings.

With a constant temperature difference through the sample the heat conductivity can be determined. The enthalpy-temperature curve of a sample is measured similar to DSC measurements by heating up and cooling down the copper plates in parallel at a certain heating rate or in stepwise mode. Additionally the apparatus allows measurements at a constant heat flux to directly determine the temperature reduction compared to conventional construction materials.

For dynamic measurements both copper plates can be tempered with individual temperature or heat flux profiles. This allows simulating the behaviour of a construction material under more realistic conditions in comparison to different systems or materials.

\subsection{Simple Thermal Analyser}

The calorimeter and measurement technique were developed at the Warsaw University of Technology (Poland) to allow determination of thermal capacity of PCMs (latent heat and specific heat of both solid and liquid phases), temperature of phase change and also identification of subcooling during solidification [20]. The volume of sample cell is $40 \mathrm{~cm}^{3}$, so relatively large samples (as compared to DSC) are investigated in this set-up. Temperature range is from $20^{\circ} \mathrm{C}$ to $300{ }^{\circ} \mathrm{C}$. A typical load cycle for PCM E22 is shown in Figure 18. 
The scheme of the calorimeter is shown in Figure 19. The sample of material is inserted into

cylindrical container, in the center of which there is an electrical heater. This vessel is enclosed in larger one which is filled with insulation powder. External surface of larger vessel is wrapped with heating wire. Voltage applied to this heater is proportional to the temperature difference between walls of internal and external vessels - measured by differential thermocouple (which is shown on the right side of the calorimeter. This kind of active insulation reduces heat losses from the calorimeter, thus increasing accuracy of measurement. The set of two vessels is put inside big container which is filled with additional layer of insulation.

Despite the complex thermal insulation of the sample cell, heat losses to the environment are substantial (especially in high temperatures), and they cannot be ignored in quantitative analysis. In order to get information on heat losses the calorimeter was calibrated. Based on the measurements of the set of reference materials (of well-known thermal properties) its characteristics - heat losses as a function of the temperatures of internal vessel and internal heater - were determined.

The measurement procedure is based on the heating of the sample with constant power. During this heating phase temperatures in selected points of the calorimeter are recorded, i.e. thermocouples are placed on the surface of internal (main) heater, inside PCM, and on the external surface of the main vessel (which contains PCM). An example temperature vs. time curve (thermocouple inside PCM) is shown in Figure 20. In the heating period three sub-ranges can be easily distinguished. The first one corresponds to the heating of solid phase of PCM. Then melting starts and the slope of temperature curve is very close to zero. After the sample completely melts, heating of liquid phase occurs.

Knowing heat flow from the heater (its power), heat losses to the environment (from the calibrations curves), sample mass and temperature increase rate specific heat of solid phase (firs sub-region) and liquid phase (third sub-region) can be determined. Position of temperature plateau in the second sub-range and the time-length of this period allow determination of phase change temperature (melting point) and latent heat. More detailed analysis of temperature curve obtained during measurement give the characteristic of enthalpy vs. temperature for material under test.

Heating is finished when temperature of the sample reaches certain level. Internal heater is turned off and cooling of the sample begins. Due to very good thermal insulation this stage of the process is very slow and possible subcooling can be observed. Since heat fluxes in this stage 
are not controlled quantitative properties (e.g. enthalpy changes vs. temperature) cannot be determined.

\subsection{Thermal test device}

New equipment with high flexibility to perform different experiments to test steady and transient thermal response of real constructive systems, including those containing PCM was developed at the University of Lleida (Spain) [21].

The new equipment (Figure 21) is based on a wooden structure and has dimensions of $50 \mathrm{~cm} \mathrm{x}$ $50 \mathrm{~cm}$ x $118 \mathrm{~cm}$. The exterior wood panels $(3 \mathrm{~mm})$ are insulated with $16 \mathrm{~cm}$ of polystyrene $(\mathrm{k}=$ $0.034 \mathrm{~W} / \mathrm{m} \cdot \mathrm{K}$ ), and its interior is divided into two cavities, which are used to simulate the inner and outer conditions of a building envelope (walls or roofs). The sample to be tested is placed between these two cavities with its four edges well insulated (panels of polystyrene were also used along the four edges of the sample to ensure one-dimensional heat flux conditions). Both cavities had a copper cooling coil connected to programmable water baths, those water baths are able to simulate different thermal conditions, such as daily variation of ambient temperature, controlled temperature in the cavity and different heating and cooling ramps.

The location of the used sensors is shown in Figure 22. The temperatures in each cavity were measured using calibrated Pt-100 DIN B with a maximum error of $\pm 0.3^{\circ} \mathrm{C}$, while the surfaces and centre of the sample were measured using thermocouples type $\mathrm{T}$, with an error of $\pm 0.75 \%$. Moreover, two heat flux sensors were fixed at the sample surfaces to measure input and output heat flux (Hukseflux HFP01). These heat flux sensors have an accuracy of $\pm 5 \%$. The tested samples have the dimensions of $19 \times 19 \mathrm{~cm}$ with varying thickness (depending on the construction system to be tested).

Three different types of experiments can be carried out to evaluate the thermal performance of the samples previously described. The first experiment was carried out to calculate the sample thermal transmittance in steady-state, also known as U-value. The heat storage capacity or thermal mass of the tested sample was measured in the second experiment and the third experiment was done to evaluate the dynamic thermal response under daily temperature oscillation. 
- Experiment 1: Steady-state conditions.

In this experiment the sample is placed at $20^{\circ} \mathrm{C}$ in the equipment with its gypsum surface facing the lower environment. A heating ramp is programmed using water bath $\mathrm{B}$ (from $20^{\circ} \mathrm{C}$ to $50^{\circ} \mathrm{C}$ ), hence the sample is heated from below, while water bath $\mathrm{A}$ is used to keep the temperature in the upper section constant $\left(20^{\circ} \mathrm{C}\right)$. The U-value of the multilayered sample can be calculated from this experiment using of the thermal gradient between surfaces in steady-state conditions:$$
\frac{\dot{q}_{\text {sample }}}{A}
$$

where, $T_{\text {down }}$ and $T_{\text {up }}$ are the surface temperatures and

is the measured heat flux across the sample per $\mathrm{m}^{2}$, this value is calculated as an average between the heat flux measured in the top and bottom surfaces whenever they are not exactly equal. The experimental values of the thermal transmittance in steady-state have a relative error of $8 \%$ due to the propagation of errors in the measurement devices.
\end{abstract}

As example, the evolution through time of the temperature profiles in two tested samples without PCM (sample 1) and with impregnated RT27 (sample 2) are shown in Figure 23. The effect of PCM is clear during the first 6 hours, reducing the ramp of the upper and center temperature of sample 2 .

- Experiment 2: Heat storage capacity.

In this experiment the sample is placed as in the previous one and was heated up from an initial temperature of around $20^{\circ} \mathrm{C}$ (similar to the comfort temperature) to more than $40^{\circ} \mathrm{C}$ (outer peak temperature in Mediterranean summer weather) by programming heating ramps in both cavities. Note that the sample is set at uniform temperature at the initial and final conditions; therefore an average heat storage capacity of the sample can be determined from this experiment since there is no temperature gradient in the sample at the end of the experiment.

The heat flux per $\mathrm{m}^{2}$ passing through top and bottom surfaces of the sample were measured, hence the amount of heat stored in the sample can be known at any time from the difference of these two fluxes. Since the sample temperature increases at all locations from $T_{i}$ to $T_{f}$, its average heat capacity (sample $\mathrm{Cp}$ ), can be calculated as follows with a relative error of $8 \%$ : 
where $\mathrm{q}_{\mathrm{acc}}$ is the amount of heat accumulated in the sample during the experiment, and $\mathrm{m}_{\text {sample }}$ is the mass of the sample.

The following equations are used to calculate the amount of heat stored by the PCM and by the other materials of the sample (wood, glue and gypsum):

$$
\begin{aligned}
& q_{R E S T}=\left(m_{\text {sample } 2}-m_{P C M}\right) C p_{\text {sample } e_{-} 1} \cdot\left(T_{f}-T_{i}\right)_{\text {sample } 2} \\
& q_{P C M}=q_{T O T}-q_{R E S T}
\end{aligned}
$$

where $\mathrm{q}_{\mathrm{TOT}}$ is the total heat stored by the sample, $\mathrm{q}_{\mathrm{PCM}}$ is the heat stored by the PCM and $\mathrm{q}_{\mathrm{REST}}$ is the amount of heat stored by the wood and gypsum without PCM.

The rate of heat accumulation for two tested samples is shown in Figure 24.

- Experiment 3: Dynamic thermal response.

The dynamic thermal response of the tested construction sample was evaluated in the third experiment. The sample was placed with the gypsum surface facing the lower environment, simulating a roof separating the outer (upper cavity) and the inner environmental conditions (lower cavity). The temperature at the upper cavity was driven by a programmable water bath which will create high temperature daily oscillation between $42^{\circ} \mathrm{C}$ and $15^{\circ} \mathrm{C}$ in the upper cavity. The water bath B will not be used during this experiment; hence the lower cavity will be in free floating conditions. The thermal response of the sample was evaluated by analyzing the delay between peaks of the inner and outer temperature and heat fluxes, and by evaluating the dampening of the temperature wave (thermal stability coefficient), which will be calculated as the ratio between the inner and outer thermal amplitudes. Surface temperatures will be used to calculate this parameter.

The dynamic thermal response of the samples under an outer daily oscillation can be evaluated and is shown in the surface temperature evolution through time of the tested samples (Figure 25). Nevertheless, instead of comparing the delay of inner and outer temperature peaks, the time 
lag between the outer temperature and the inner heat flux peaks (thermal lag) is usually evaluated (Figure 26).

An inter-laboratory experience was carried out [22] using the thermal test device developed at University of Lleida presented above [21], the Conductimeter developed at University of Barcelona which is able to analyze the effective thermal conductivity [19] and an equipment developed at University of Castilla-La Mancha [23]. The obtained results were compared and are consistent.

\subsection{Energy Balance Setup}

Although this device (see Figure 27) was designed at the University of Zaragoza (Spain) for the analysis of heat transfer between PCM and air flow, also it can be employed to obtain h-T curves. When sample are bigger than those employed in the T-history, the energy balance can be used to obtain the enthalpy-temperature curves. The experimental rig consists of a closed air loop with a storage unit. The air in the loop can be heated and cooled artificially. A PID controller regulates the inlet air temperature in the storage unit. The temperature of the air is measured at the entrance and exit of the storage, using five calibrated Pt100 (uncertainties < $0.05^{\circ} \mathrm{C}$ ) in each point; air flow is measured using a calibrated flowmeter (uncertainty $<0.5 \%$ ). All data are stored and evaluated with tailor-made software and detailed results are published $[24,25]$.

\subsection{PCM-air heat exchangers set-up}

An experimental setup was designed at the University of Zaragoza (Spain) to study different air to PCM heat exchangers (Figure 28) [26-29]. A closed air loop setup is used to simulate indoor conditions. Setup design was based on ANSI/ASHRAE STANDARD 94.1-2002 "Method of Testing Active Latent-Heat Storage Devices Based on Thermal Performance".

This setup consists of an inlet air conditioner allowing the simulation of different operating modes ( $5 \mathrm{~kW}$ air chiller and $4.4 \mathrm{~kW}$ electrical resistance), an air flow measurement apparatus, a difference between inlet and outlet air temperatures measurement (thermopile), an inlet and outlet air temperature and humidity measurement, a PCM and air channels temperature measurement (over 20 thermocouples), a data logger and data screening, air ducts and gates, and a PID controller. 
The energy balance of air between the inlet and the outlet of the prototype is used for cooling

$$
\dot{\mathrm{Q}}=\dot{\mathrm{m}}_{\mathrm{air} \mathrm{HX}} \cdot \Delta \mathrm{h}_{\mathrm{air}} \simeq \dot{\mathrm{m}}_{\mathrm{air} \mathrm{HX}} \cdot \mathrm{c}_{\mathrm{p}_{\text {air }}} \Delta \mathrm{T} \quad \text { Eq. } 16
$$

- Air temperature difference: Thermopile. There are three difficulties to solve in this measurement: a long period of time with small temperature difference, temperature distributions in air ducts because of its dimensions and accuracy is needed because it is a main parameter of evaluation. ANSI/ASHRAE standard recommends a thermopile to solve this problem. It was chosen because it solves these difficulties. Thermocouples are designed to measure direct temperature difference between two temperature junctions. Since a thermopile is constructed by using several junctions in series of calibrated thermocouple wire, the output signal is amplified by the number of junctions, so sensibility is increased. In this case, a six junction thermopile is used. In order to have representative measurements of air temperature difference, each junction is located at the center of equal cross section areas. Therefore, the temperature difference is measured involving the complete sectional area. Precision is then $0.51{ }^{\circ} \mathrm{C}$, better than when using two Pt100 $\left(0.65^{\circ} \mathrm{C}\right)$ and also sensibility and temperature distribution evaluation are improved.

- Air flow: energy balance of electrical resistances. Air temperature changes during a test, therefore most of air flow measurements methods are not suitable for transitory measurements. Mass flow depends only on fan velocity, therefore it is measured by applying an energy balance on electrical resistance. The maximum power is set to electrical resistances. The energy consumption is measured with a $1 \%$ uncertainty and air temperature difference caused in the air by passing through the electrical resistances is measured by a thermopile with an accuracy of $0.51^{\circ} \mathrm{C}$.

- Air humidity: two sensors are used to measured air humidity at the inlet and the outlet. The maximum air humidity variation during a test was $0.006 \mathrm{~kg} / \mathrm{kg}_{\mathrm{da}}$. It is lower than the $0.2 \%$ of total stored energy, therefore, it was confirmed that latent energy variation is negligible in energy balance of air for cooling power evaluation. 
Figure 29 shows the comparison between the experimental results and the simulation results for a PCM-air heat exchanger tested in the experimental set-up.

As a result of the different testing procedures it can be evaluated:

1. The stored energy as a function of temperature in the system.

2. The numerical model validation.

3. The empirical model of the system where the heat transfer rate in dependence on time is obtained as a function of the system temperature and the air temperature.

A similar approach can be followed with bigger installations, such as the one available at the University of Lleida (Figure 30) [30].

\subsection{Test room from Fraunhofer}

For real size testing of construction materials an adiabatic test room was installed at Fraunhofer ISE (Germany) (Figure 31). The test room is designed to measure the performance of a PCM system (especially floor heating systems and chilled ceilings) in direct comparison with conventional construction materials under controlled conditions in a 1:1 scale. Tests with different temperature or heat flux profiles where carried out to characterize the performance of active PCM systems. Also the heat storage capacity of a system gets calculated from the measurement results.

The test room was set up according EN 14240:2004 and DIN 4715 with an inner size of $4 \times 4 \times 2.7 \mathrm{~m}(\mathrm{LxW} \times \mathrm{H})$. Each surface of the room is controlled individually to decrease losses to the ambient and simulate heat flow in different independent directions. The test room is installed directly behind the façade of the building. By removing the south oriented wall of the test room the original façade of the building can be used for measurements under real conditions. Inside the room electrical heating or cooling devices can be installed to simulate the heating and cooling loads.

\section{Thermal diffusivity and thermal conductivity}

\subsection{Commercial equipment for thermal conductivity determination}

At the University of Zaragoza (Spain), thermal conductivity is measured using a Laser Flash (LFA). In Laser Flash method the sample is placed between the Flash Lamp and the IR detector. The Laser pulse come into contact with one surface of the sample and the IR detector measures 
the temperature variation at the opposite surface. By a mathematical treatment of this temperature evolution, the thermal diffusivity of the sample is obtained. From LFA measurements, thermal conductivity is obtained with:

$$
\lambda=\rho \cdot c_{p} \cdot \alpha \quad \text { Eq. } 17
$$

where $\lambda$ is the thermal conductivity $[\mathrm{W} /(\mathrm{m} \cdot \mathrm{K})], \rho$ is the density $\left[\mathrm{kg} / \mathrm{m}^{3}\right], \mathrm{cp}$ is the specific heat $[\mathrm{kJ} /(\mathrm{kg} \cdot \mathrm{K})]$, and $\alpha$ the thermal diffusivity $\left[\mathrm{m}^{2} / \mathrm{s}\right]$.

At the Institute of Physical Chemistry of the Romanian Academy (Romania), two different commercial instruments are available, used for different sample mass.

First, thermal conductivity was determined with an UNITHERM 6000 setup in stationary regime. The thermal conductivity was calculated from [31]: $\mathrm{k}=\mathrm{q} \cdot \mathrm{a} / \Delta \mathrm{T}$, where $\mathrm{k}$ is thermal conductivity, density of thermal flux, $\mathrm{q}$, in $\mathrm{W} / \mathrm{m}^{2}$, a is the thickness of the plate, and $\Delta \mathrm{T}$ is the temperature difference between the plate faces. Based on the thermal response as a temperature variation at an adiabatic surface and by means of the same experimental set-up UNITHERM 6000 , thermal diffusivity coefficients were calculated using the relationship: $a=25 \cdot \mathrm{k} \cdot \mathrm{V} / \mathrm{K} \cdot \mathrm{A}$, where $\mathrm{k}$ is thermal conductivity, $\mathrm{V}$ and $\mathrm{A}$ are volume and surface of the specimen, and $\mathrm{K}$ is a shape dependent coefficient. Figure 32 shows the analysis of the composite PEG1500-Epoxy [32].

For small samples another conductivimeter was used, the $\mathrm{TCI}^{\mathrm{TM}}$ Thermal Conductivity analyser (C-THERM technologies) based on the modified plane source technique. The sensor is optimally engineered for the testing of liquid and powders, but can also test solid materials across a wide range from foams to metals. The sensor is highly sensitive scientific device. The TCI software temperature monitoring function may be used to verify temperature stability in real-time.

Small cylinders of samples $(1.8 \times 1=\mathrm{d} \times \mathrm{h})$ were tested for thermal conductivity and effusivity by means of a C-Therm TCi Analyzer, at room temperature. The Thermal Analyzer was calibrated against the Pyrex reference. Silicon oil was employed as contact agent. The obtained values are $15 \%$ higher, probably due to the pyrex standard used and due to the contact fluid different of water. 


\subsection{Non-commercial meso-scale set-up}

A periodical method was used at CERTES (France) to estimate thermal conductivity, diffusivity and specific heat of polymer composite materials at room temperature [33,34] and as a function of temperature. Micronal ${ }^{\circledR}$ DS $5001 \mathrm{X}$ from $\mathrm{BASF}^{\circledR}$ with a melting temperature of $26^{\circ} \mathrm{C}$ has been used as the active CM component. The microcapsules of paraffin encapsulated in crosslinked PMMA were mixed with polycaprolactone (PCL) to form composites. Several sets of mixtures were made for mass concentrations over the range of 10 to $50 \%$. The mixtures were blended in the $30 \mathrm{ml}$ mixing chamber of a blending machine at the Polymer Institute of Slovak Academy of Sciences (Slovakia).

A schematic representation of the experimental set up is shown in Figure 33. This method is based on the use of a small temperature modulation in a parallelepiped-shape sample (44 $\mathrm{mm}$ of side and $2.5 \mathrm{~mm}$ of thickness) and allows obtaining all of these thermophysical parameters in only one measurement with their corresponding statistical confidence bounds.

The sample was fixed between two metallic plates. The front side of the first metallic plate was heated periodically using a sum of five sinusoidal signals and the temperature was measured with thermocouples placed inside both front and rear metallic plates. A temperature control system has been used in order to perform the measurement as function of temperature $\left(-20^{\circ} \mathrm{C}<\right.$ $\mathrm{T}<180^{\circ} \mathrm{C}$ ). The thermophysical parameters of the sample were identified by comparison of the experimental and theoretical heat transfer functions. The system under study was modelled with one-dimensional quadrupoles theory. The experimental heat transfer function was calculated at each excitation frequency as the ratio between the Fourier-transform temperatures of the front and rear plates. A parameter estimation technique was then applied to estimate simultaneously both thermal conductivity $(\lambda)$ and diffusivity $(\alpha)$. The identification of the set of thermophysical parameters is a non-linear optimization problem that is solved iteratively: starting with sufficiently accurate initial guesses for the unknown parameters, we successively refine the estimates by using the Levenberg-Marquardt method.

The specific heat capacity $(C p)$ values of the composite samples can be determined using thermal conductivity and diffusivity values and knowing the density, $\rho$ :

$$
c_{p}=\frac{\lambda}{\rho \cdot a}
$$


The evolution of thermal conductivity and diffusivity as a function of temperature of for one sample with a weight fraction of microencapsulated paraffin of $40 \%$ (Figure 34). On these results, thermal conductivity $(\lambda)$ and diffusivity $(\alpha)$ values has been taken at $-10^{\circ} \mathrm{C}$ and $35^{\circ} \mathrm{C}$ on all composites. These temperatures were chosen where none endothermic phenomenon has been observed in DSC. The initial objective was to obtain the thermophysical properties of composites outside phase change temperature ranges, when the paraffin is solid and liquid.

Microcapsules, PCL and composites were studied by DSC between $-20{ }^{\circ} \mathrm{C}$ and $75{ }^{\circ} \mathrm{C}$ at 10 ${ }^{\circ} \mathrm{C} / \mathrm{mn}$. For paraffin microencapsulated in PMMA two endothermic peaks are observed. The first peak located at $2{ }^{\circ} \mathrm{C}$ corresponds to a solid-solid phase transition in paraffin. The second peak corresponds to the melting of the paraffin with an onset temperature near $26{ }^{\circ} \mathrm{C}$. PCL is a semi-crystalline polymer, its melting was observed around $60^{\circ} \mathrm{C}$.

First we notice that thermal conductivity $(\lambda)$ and diffusivity $(\alpha)$ are higher at $-10{ }^{\circ} \mathrm{C}$ than at 35 ${ }^{\circ} \mathrm{C}$. So the influence of the temperature on thermophysical properties of composites is not negligible. It is observed that the thermal conductivity decreases with increasing temperature which is normal because, on the one hand, for a semicrystalline polymer, the thermal conductivity decreases steadily with increasing temperature below the melting point and, moreover, paraffin see also a reduction of its thermal conductivity especially when it changes its state from solid to liquid (i.e. above $26{ }^{\circ} \mathrm{C}$ ). As visible in Figure 35 , at $-10^{\circ} \mathrm{C}$, an increase of thermal conductivity $(\lambda)$ and thermal diffusivity $(\alpha)$ with increasing filler volume fraction was observed, while at $35^{\circ} \mathrm{C}$ the opposite happens.

\subsection{Energy balance setup: thermal effect of addition of PCM in components determination}

By modifying the energy balance setup available at the University of Zaragoza (Spain) described previously (Figure 27), it could be used to study thermal response of building materials or big samples [35]. This modification consists on building an insulated enclosure where sample is placed so that only one surface is exposed to the air flow. Air flow is then bypassed (Figure 36). Temperature is measured at three points: center of insulated surface, center of exposed surface, and air temperature at center of exposed surface. Air temperature is maintained constant by a PID controller. Air flow is measured and set at the same rate for all experiments. Temperatures are registered and then could be compared its evolution for different samples in equal conditions. In order to evaluate thermal response time effect due to PCM, a 
reference without PCM is used. Then, the sample containing PCM is measured in equal conditions (initial temperature of the samples, airflow rate and air temperature).

\subsection{Macro-scale conductivimeter}

The development of this equipment was done at the University of Barcelona (Spain) following the UNE-EN 12664, for measuring thermal resistance by means of guarded hot plate [19]. Two samples $(300 \times 300 \times 30 \mathrm{~mm})$ in sandwich configuration have a heating plate and two cooling exterior plates (Figure 37). Five thermocouples are for measurement and verification, and 24 type $\mathrm{K}$ in the central zone and between central and external zone. The temperature is stabilized in steady state conditions and the effective thermal conductivity is measured at a fixed temperature.

During the Conductimeter experiments, the samples were heated applying $15 \mathrm{~V}$ at the hot plate resistance with the power supply while the water bath was used to keep constant the temperature on the cold plate section. These conditions were maintained until steady state conditions. At this stage, the cold and hot surface temperatures were used to calculate the thermal conductivity of the sample. The results are shown also in Figure 37.

\subsection{Heat transfer coefficient of PCM slurries and emulsion}

An experimental setup was designed and constructed at the University of Zaragoza (Spain) to measure the convective heat transfer and the pressure drop of the microencapsultated PCM (mPCM) slurry flowing through a circular tube [36,37]. Specifically, the experimental setup allows for obtaining local convective heat transfer coefficients under constant heat flux in a tube. Figure 38 shows the schematic diagram of the experimental setup, which consists of a thermostatic bath, a Coriolis flow meter, a hydrodynamic entry section, a heat transfer section, a pump and control valves. In addition to the convective heat transfer coefficient, the pumping of PCM slurries and emulsions will allow the subsequent study of their technical viability under thermal-mechanical loads.

The Fraunhofer Institute for Solar Energy Systems developed a test bench to investigate the behavior of Phase change slurries (PCS) under simulated real-world conditions. All installed components are used in standard hydraulic networks for cooling and heating applications. The test bench can be operated with all kind of fluids as emulsion or suspensions. Fluids can be characterized on thermal and hydraulic properties and on cycle stability. The thermal heat transfer characteristics of fluids using heat exchangers can be determined. Installed pressure 
sensors can measure the differential pressure of one heat exchanger under different working conditions (temperatures, volume flows). The fluid is continuously heated and cooled down in the test bench; therefore long-term tests can be made concerning the cycle stability of the PCS. Figure shows a sketch of the test facility with three different hydraulic loops. In the central loop (test loop) the investigated fluid circulates and gets heated up by a heat exchanger on the left side (heating loop) and cooled down in the second heat exchanger (cooling loop) on the right side. Outlet temperatures of the heat exchangers in the test loop can be controlled by thermostats (heater and chiller).

A centrifugal pump (Speck Pumpen Walter Speck GmbH \& Co. KG, MY2-8000) conveys the test fluid. Volume flows can be controlled continuously variable within the operation limits of the centrifugal pump. To analyze the influence of mechanical strength caused by the pump on molten or solid PCM in the capsules, the pump can be installed on the side of the heated or cooled fluid.

Plate heat exchangers of API Schmidt-Bretten GmbH \& Co. KG (SIGMA M 7 NBL) are installed to transfer heat between the test loop and the heating/cooling loop. Heat exchangers are operated according to the counter current flow principle. On the heating side the heat exchanger contains 8 plates with a heat exchange surface of $0.4 \mathrm{~m}^{2}$, on the cooling side 10 plates with 0.5 $\mathrm{m}^{2}$, respectively. Heating energy is provided by a thermostat of Weinreich Industriekühlung GmbH (WTD 6) with a maximum power output of $9 \mathrm{~kW}$. The chiller (meding Lab, KK $150 \mathrm{w}$ ) has a maximum power output of $10 \mathrm{~kW}$.

Temperature is measured on each inlet and outlet of the heat exchangers using Pt-100 sensors. Magnetic inductive flow meters are installed in all three hydraulic loops. Two pressure sensors are installed on the test loop side at the cooling heat exchanger to determine the differential pressure.

Water is used as heat transfer fluid in the heating loop, the cooling loop is operated with a water-glycol mixture. Since the thermodynamic properties as density and specific heat capacity of water and of the water-glycol mixture are well known, heat fluxes from the heating/cooling loops into the test loop can be calculated by using the measured quantities volume flows and temperatures. With the installed pressure sensors, changes of hydraulic properties can be observed. If capsule rupture occurs due to mechanical stress or the rheological behavior changes over time, pressure changes can be observed. The duration of extended time tests can be reduced with this test bench and cycle stability of the test fluids can be analyzed. 


\section{Conclusions}

This paper presents different instruments to characterize thermophysical properties of PCM. The available home-made equipment show the difficulty in such characterization and the impossibility of carrying it out with commercial instruments for samples in the meso and the macro scale. Also, the equipment described in this paper shows the importance of a correct characterization of not only the materials used as PCM, but also of the hybrid composites, those which are actually used in buildings.

The laboratories authoring this paper have participated in the European COST Action TU0802, developing a stable network of scientists that today exchange not only samples to be characterized, but also students and researchers to potentiate the research carried out.

\section{Acknowledgements}

The work is partially funded by the European Union (COST Action COST TU0802), the Spanish government (ENE2011-28269-C03-01, ENE2011-28269-C03-02 and ENE201122722), TUBITAK (project 110M032), and by Qatar National Foundation through the NPRP No.: 4-465-2-173. The authors would like to thank the Catalan Government for the quality accreditation given to the research group GREA (2009 SGR 534) and their research group DIOPMA (2009 SGR 645), both in Spain. Laia Miró would like to thank the Spanish Government for her research fellowship (BES-2012-051861).

\section{References}

1. Zalba B, Marín JM, Cabeza LF, Mehling H. Review on thermal energy storage with phase change: materials, heat transfer analysis and applications. Applied Thermal Engineering 2003;23:251-83.

2. Farid MM, Khudhair AM, Razack SAK, Al-Hallaj S. A review on phase change energy storage: materials and applications. Energy Conversion and Management 2004;45:1597615.

3. Khudhair AM, Farid MM. A review on energy conservation in building applications with thermal storage by latent heat using phase change materials. Energy Conversion and Management 2004;45:263-75.

4. Tyagi VV, Buddhi D. PCM thermal storage in buildings: a state of art. Renewable and Sustainable Energy Reviews 2007;11:1146-66. 
5. Kenisarin M, Mahkamov K. Solar energy storage using phase change materials. Renewable and Sustainable Energy Reviews 2007;11:1913-65.

6. Sharma A, Tyagi VV, Chen CR, Buddhi D. Review on thermal energy storage with phase change materials and applications. Renewable and Sustainable Energy Reviews 2009;13:318-45.

7. Cabeza LF, Castell A, Barreneche C, de Gracia A, Fernández AI. Materials used as PCM in thermal energy storage in buildings: A review. Renewable and Sustainable Energy Reviews 2011;15:1675-95.

8. Fernández AI, Solé A, Giró J, Martínez M, Hadjuieva M, Boudenne A, Constantinescu M, Anghel EM, Malikova M, Krupa I, Peñalosa C, Lázaro A, Paksoy HO, Cellat K, Vecstaudza J, Bajare D, Sumiga B, Boh B, Haussmann T, Gschwander S, Weber R, Furmanski P, Jaworski M, Cabeza LF. Unconventional technologies used for phase change materials (PCM) characterization. Part 2. Morphological and structural characterization, physico-chemical stability and mechanical properties. Renewable \& Sustainable Energy Reviews, 2014, in press.

9. Lázaro A, Peñalosa C, Solé A, Diarce G, Haussmann T, Fois M, Zalba B, Gshwander S, Cabeza LF. Intercomparative tests on phase change materials characterisation with differential scanning calorimeter. Applied Energy, 2013;109: 415-20.

10. Castellón C, Günther E, Mehling H, Hiebler S, Cabeza LF. Determination of the enthalpy of PCM as a function of the temperature using a heat-flux DSC - A study of different measurement procedures and their accuracy. International Journal of Energy Research 2008;32:1258-65.

11. Barreneche C, Solé A, Miró L, Martorell I, Fernández AI, Cabeza LF. Study on differential scanning calorimetry analysis with two operation modes and organic and inorganic phase change material (PCM) Thermochimica Acta 2013;553:23-6.

12. Barreneche C, Solé A, Miró L, Martorell I, Fernández AI, Cabeza LF. New methodology developed for DSC analysis of polymeric matrixes incorporating PCM. Measurement Science and Technology 2012;23:085606.

13. Demirel Y, Paksoy HO. Thermal analysis of heat storage materials. Thermochimica Acta 1993;213:211-21.

14. Paksoy HO. Determining thermal properties of heat storage materials using the twin bath method. Energy Conversion and Management 1996;37(3):261-8.

15. Marín JM, Zalba B, Cabeza LF, Mehling H. Determination of enthalpy-temperature curves of phase change materials with the temperature-history method: improvement to temperature dependent properties. Measurement Science \& Technology 2003;14(2):184-9. 
16. Lázaro A, Günther E, Mehling H, Hiebler S, Marín JM, Zalba B. Verification of a T-history installation to measure enthalpy versus temperature curves of phase change materials. Measurement Science \& Technology 2006;17(8): 2168-74.

17. EMPA internal report Report-No 204'756, November 2005.

18. Solé A, Miró L, Barreneche C, Martorell I, Cabeza LF. Review of the T-history method to determine thermophysical properties of phase change materials (PCM). Renewable \& Sustainable Energy Reviews 2013;26:425-36.

19. Barreneche C, Navarro ME, de Gracia A, Fernández AI, Cabeza LF. Improvement of the thermal inertia of building materials incorporating PCM. Evaluation in the macroscale. Applied Energy 2013;109:421-32.

20. Domanski R, Jaworski M. Measurements of thermal properties of PCM materials. Proceedings of the $6^{\text {th }}$ International Conference on Thermal Energy Storage Calorstock'94. Espoo, Finland, 1994, pp. 487-494.

21. de Gracia A, Barreneche C, Farid MM, Cabeza LF. New equipment for testing steady and transient thermal performance of multilayered building envelopes with PCM. Energy and buildings 2011;43(12):3704-9.

22. Barreneche C, de Gracia A, Serrano S, Navarro M.E, Borreguero A.M, Fernández A.I, Carmona M, Rodriguez JF, Cabeza LF. Comparison of three different devices available in Spain to test thermal properties of building materials including phase change materials. Applied Energy 2013;109:544-52.

23. Borreguero AM, Sánchez ML, Valverde JL, Carmona M, Rodríguez JF. Thermal testing and numerical simulation of gypsum wallboards incorporated with different PCMs content. Applied Energy 2011;88:930-7.

24. Zalba B, Marín JM, Cabeza LF, Mehling H. Free-cooling of buildings with phase change materials. International Journal of Refrigeration-Revue Internationale $\mathrm{Du}$ Froid 2004;27(8):839-49.

25. Marín JM, Zalba B, Cabeza LF, Mehling H. Improvement of a thermal energy storage using plates with paraffin-graphite composite. International Journal of Heat and Mass Transfer 2005;48:2561-70.

26. Lázaro A, Dolado P, Marín JM, Zalba B. PCM-air heat exchangers for free-cooling applications in buildings: Experimental results of two real-scale prototypes. Energy Conversion and Management 2009;50:439-43.

27. Dolado P, Lázaro A, Marin JM, Zalba B. Characterization of melting and solidification in a real-scale PCM-air heat exchanger: Experimental results and empirical model. Renewable Energy 2011;36:2906-17. 
28. Dolado P; Lázaro A, Marín JM, Zalba B. Characterization of melting and solidification in a real scale PCM-air heat exchanger: Numerical model and experimental validation. Energy Conversion and Management 2011;52(4):1890-907.

29. Dolado P, Mazo J, Lázaro A, Marín JM, Zalba B. Experimental validation of a theoretical model: uncertainty propagation analysis to a PCM-Air thermal energy storage unit. Energy and Buildings 2012;45:124-31.

30. Gil A, Oró E, Peiró G, Álvarez S, Cabeza LF. Materials selection and testing for thermal energy storage in solar cooling. Renewable Energy 2013;57: 366-71.

31. Baehr HD, Stefan K. Waerme und stoffuebergang. Heidelberg: Springer Verlag Berlin; 1994.

32. Constantinescu M, Constantinescu D, Dumitrache L, Perianu Marin C, Stoica A, Ladaniuc $\mathrm{M}$, et al. Composite PEG-EPOXY as building elements. In: Proceedings of the 11th international conference on thermal energy storage - Effstock 2009, Stockholm; 2009.

33. Boudenne A, Ibos L, Gehin E, Candau Y. A simultaneous characterisation of thermal conductivity and diffusivity of polymer materials by a periodic method. Journal of Physics D: Applied Physics 2004;37:132-9.

34. Boudenne A, Ibos L, Candau Y. Analysis of uncertainties on thermophysical parameters of materials obtained from a periodic method. Measurement Science and Technology 2006;17:1870-6.

35. Lázaro A, Marín JM, Dolado P, Zalba B. Experimental setup to study thermal effects of phase change materials inclusion into building materials. Eurosun 2008, 1st International Conference on Solar Heating, Cooling and buildings. Lisbon (Portugal), October 2008.

36. Delgado M, Mazo J, Peñalosa C, Marín JM, Zalba B. Analysis of PCM slurries and PCM emulsions as heat transfer fluids. Effstock $2009,11^{\text {th }}$ International conference on thermal energy storage, Stockholm (Sweden), June 2009.

37. Delgado M, Lázaro A, Mazo J, Marín JM, Zalba B. Experimental analysis of a microencapsulated PCM slurry as thermal storage system and as heat transfer fluid in laminar flow. Applied Thermal Engineering 2012;36:370-7. 


\section{Figure captions}

Figure 1. Typical heat flow and temperature evolution during a dynamic DSC measurement with constant heating rate [11]. The peaks indicate strong thermal effects of the sample at the corresponding temperatures.

Figure 2. Typical heat flow and temperature evolution during a DSC measurement with the step method, here shown for heating [11]. Different peaks indicate different amounts of heat transferred in the respective temperature interval.

Figure 3. Graphic example of the stored heat as a function of temperature in the case of heating. The similar graphs in case of cooling must be presented too.

Figure 4. DSC profiles of the composite material with conventional blank subtracted [12].

Figure 5. DSC profile of heating process of composite sample which contains PCM using different types of blank [12].

Figure 6. Scheme of the twin bath set up developed at Çukurova University (Turkey) [13].

Figure 7. Heating and cooling curve for the sample of paraffin: (a) temperature of bath 1; (b) temperature of bath $2 ;$ (c) temperature difference between the sample of paraffin (\&) and bath 1 [13].

Figure 8. Difference between the power loads of bath 2 (P2) containing the sample of paraffin and bath 1 (P1) [13].

Figure 9. T-history the set-up available at the University of Zaragoza, Spain [16].

Figure 10. Enthalpy-temperature curves obtained for an organic and an inorganic PCM with the T-history method [16].

Figure 11. Schematic plan of the T-history setup at Empa [17].

Figure 12. Vessel used for T-history analysis at Empa [17].

Figure 13. Full cycle temperature curve with the T- history measurement method [17].

Figure 14. Left: sketch of the set up configuration to the t-T curves device. Right: thermal response of the sample from the sensor located in the center of the sample [19].

Figure 15. Schematic plan of the panel measurement box developed at Empa [17].

Figure 16. Test setup for panel testing developed at Empa [17].

Figure 17. Left: Scheme of the plate test apparatus at Fraunhofer ISE for testing construction materials in a $50 \times 50 \mathrm{~cm}$ scale. Right: Picture of the whole apparatus.

Figure 18. Typical full load cycle with PCM E22 [20]. PCM weight: $33.4 \mathrm{~kg} / \mathrm{m}^{2}$, total panel weight: $58.3 \mathrm{~kg} / \mathrm{m}^{2}$.

Figure 19. The scheme of the calorimeter for the measurement of thermal capacity properties of PCM [20].

Figure 20. Example results of the thermal analyser test [20]: Temperature indicated by the sensor inside the sample vs. time during heating and natural cooling. 
Figure 21. Sketch of the new equipment (Thermal test device) developed at the University of Lleida (Spain) [21].

Figure 22. Sensor distribution in the sample of the Thermal test device developed at the University of Lleida (Spain) [21].

Figure 23. Temperature profile of the samples during experiment 1 (1- no PCM; 2- with PCM) [21].

Figure 24. Rate of heat accumulation of both samples during experiment 2 [21].

Figure 25. Dynamic response of the surface temperatures (1- no PCM; 2- with PCM) [21].

Figure 26. Thermal lag of both samples (1- no PCM; 2- with PCM) [21].

Figure 27. Energy Balance Setup available at the University of Zaragoza (Spain) [24].

Figure 28. Experimental installation of PCM-air heat exchangers (University of Zaragoza, Spain) [26].

Figure 29. Comparison of experimental and simulated results (including their corresponding uncertainty bands) of a full thermal cycle. Left: melting stage; right: solidification stage [27].

Figure 30. Pilot plant available at the University of Lleida [30].

Figure 31. Inside view of the adiabatic test room at Fraunhofer ISE with an installed PCM chilled ceiling.

Figure 32. Thermal conductivity analysis of PEG composite carried out at the Institute of Physical Chemistry of the Romanian Academy [32].

Figure 33. Schematic representation of the experimental setup allowing obtaining simultaneously thermal conductivity and diffusivity available at CERTES, France [33].

Figure 34. Evolution of thermal conductivity and diffusivity as a function of temperature of PCL/microencapsulated paraffin composites (60\%/40\% wt.) measured at CERTES, France.

Figure 35. Variation of thermal conductivity (left) and thermal diffusivity (right) of $\mathrm{PCL} /$ microencapsulated paraffin composites as function of microcapsules volume fraction at $10{ }^{\circ} \mathrm{C}$ and $35{ }^{\circ} \mathrm{C}$ measured at CERTES, France.

Figure 36. Energy Balance configuration to test thermal diffusivity at the University of Zaragoza (Spain) [35].

Figure 37. Left: experimental set up. Right: Experimental results for a gypsum and Portland cement matrixes incorporating different amount of PCM [19].

Figure 38. Picture of the experimental setup for slurries characterization available at the University of Zaragoza (Spain) [37].

Figure 39. Test facility setup available at Fraunhofer ISE (Germany) for PCS. 


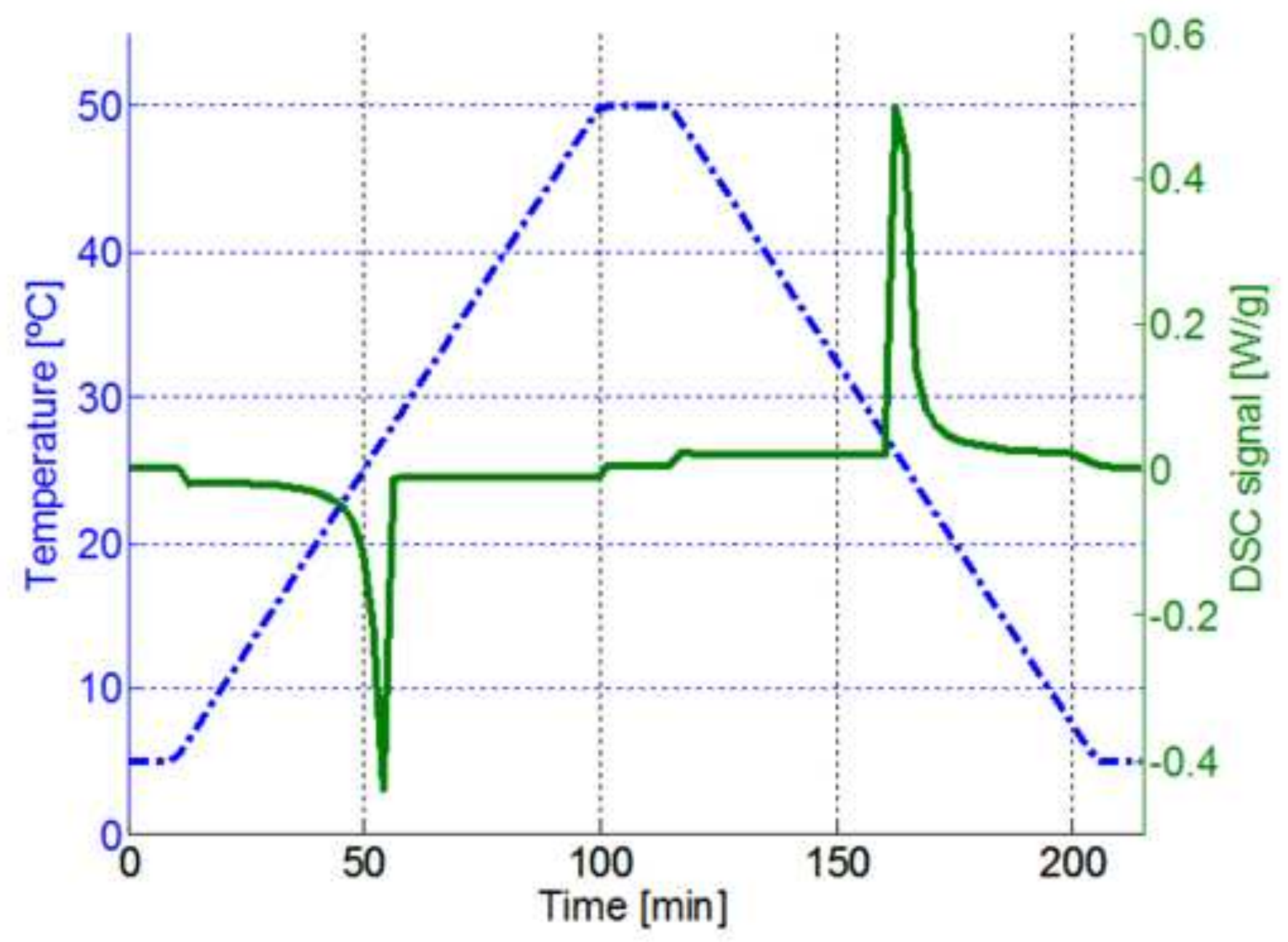

Fig. 1 


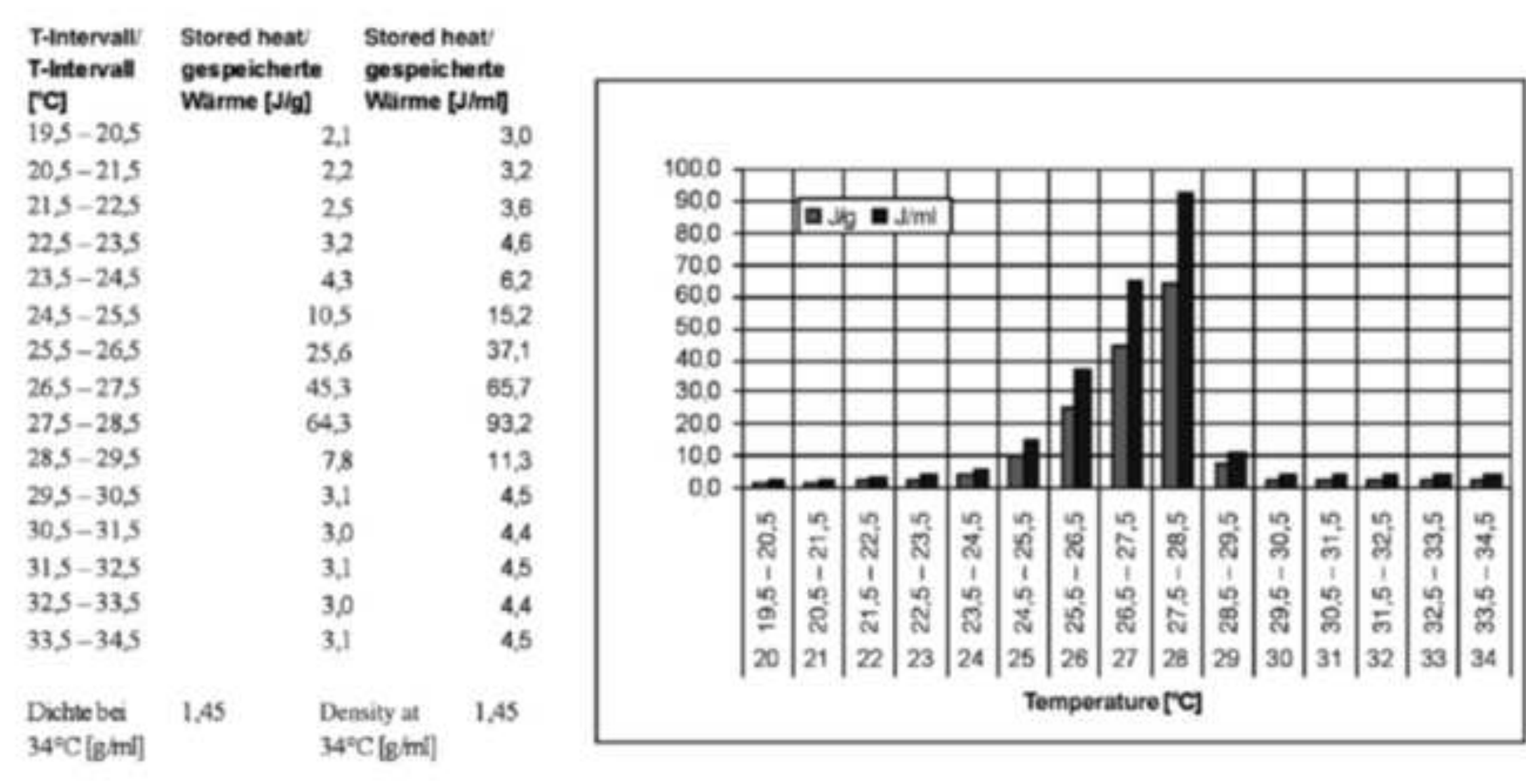

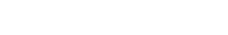
Temperature $[\mathrm{C}]$

\section{Fig. 3 \\ Fig. 3}

$34^{\circ} \mathrm{C}[\mathrm{g} / \mathrm{ml}]$ $34^{\circ} \mathrm{C}[\mathrm{g} / \mathrm{m}]$

Stored heat

peichert: 3,0 3.2 3,6

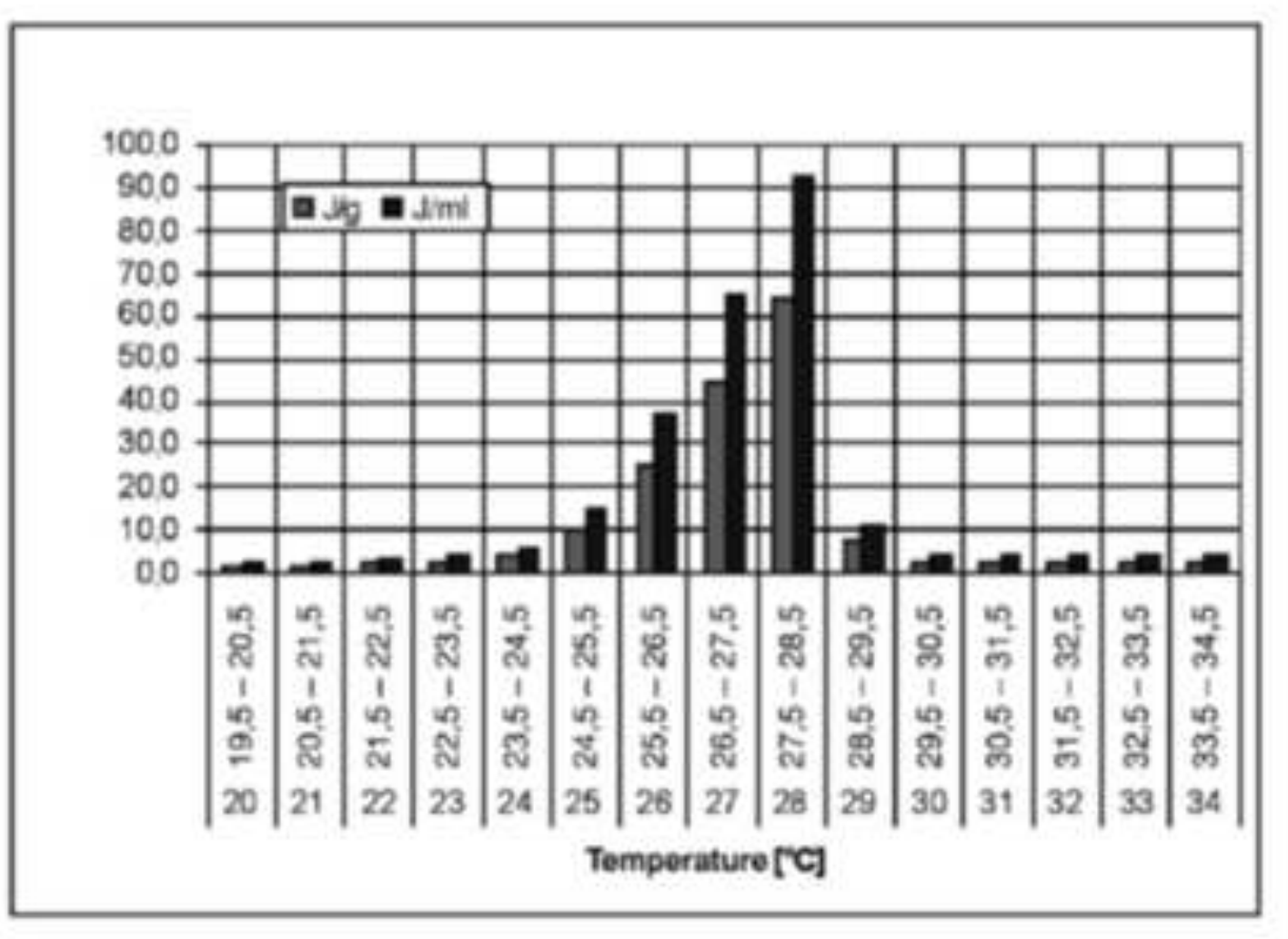

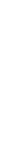

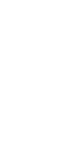

(a)

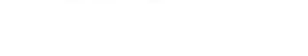

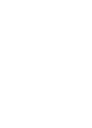

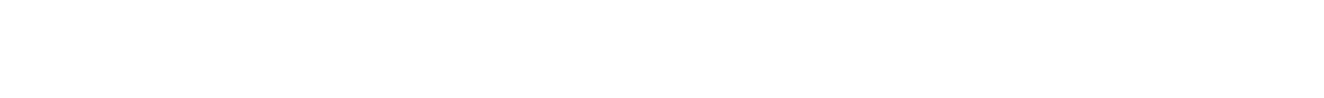

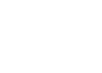
(a) 
Click here to download high resolution image

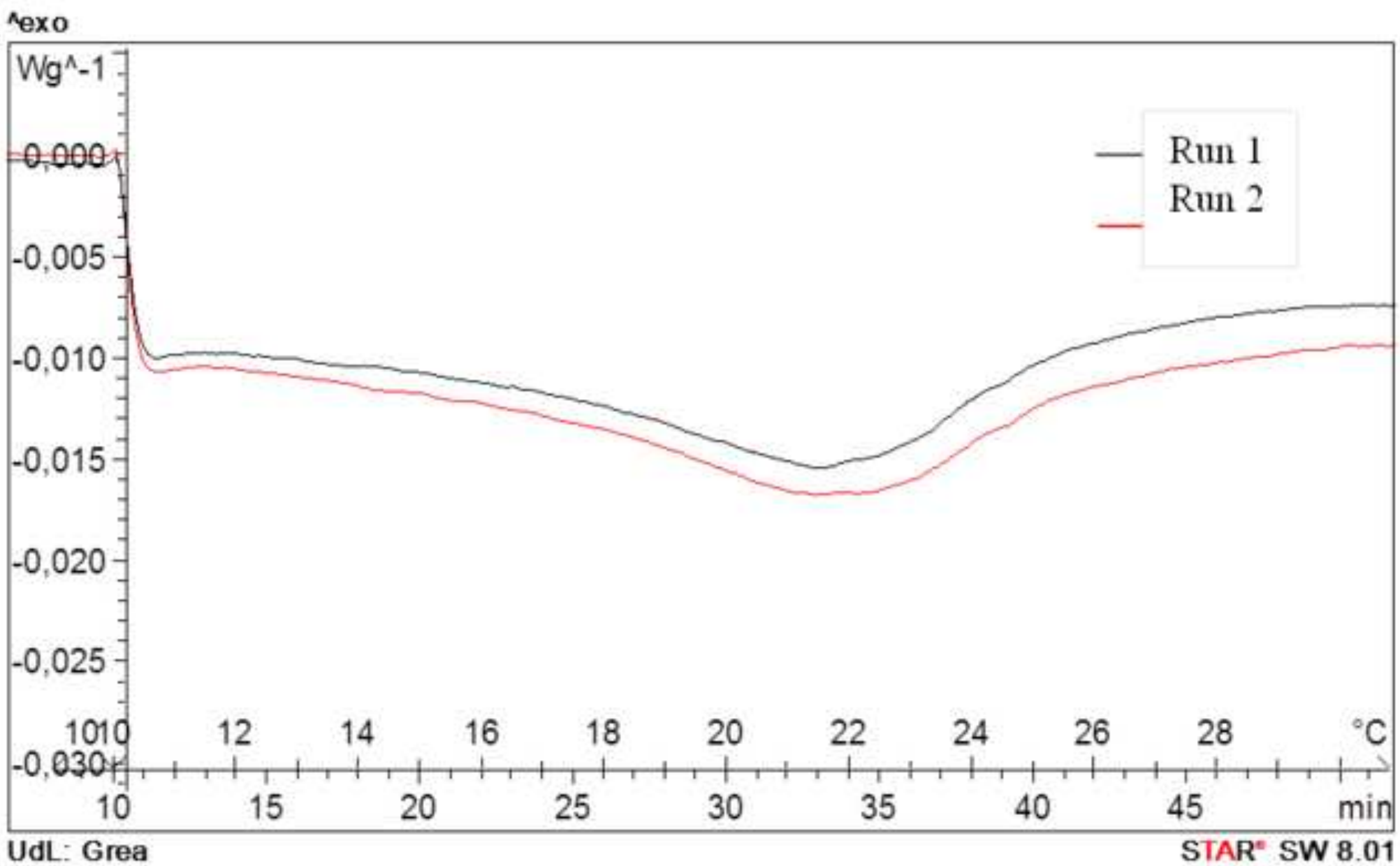

Fig. 4

exo 


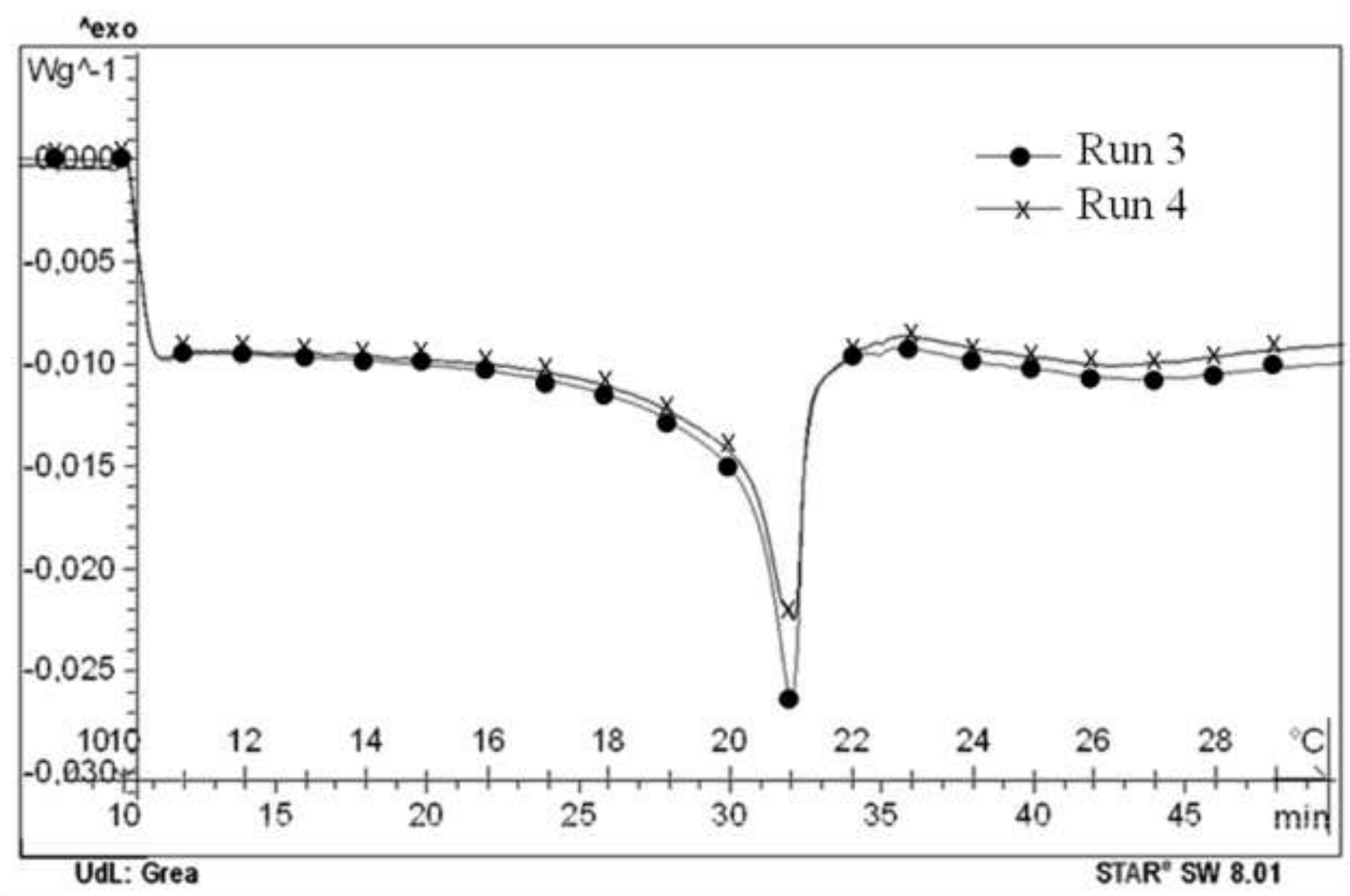

Fig. 5

Figure
Click here to download high resolution imag

UdL. Grea

STAR ${ }^{0}$ SW 8.01 
Click here to download high resolution image

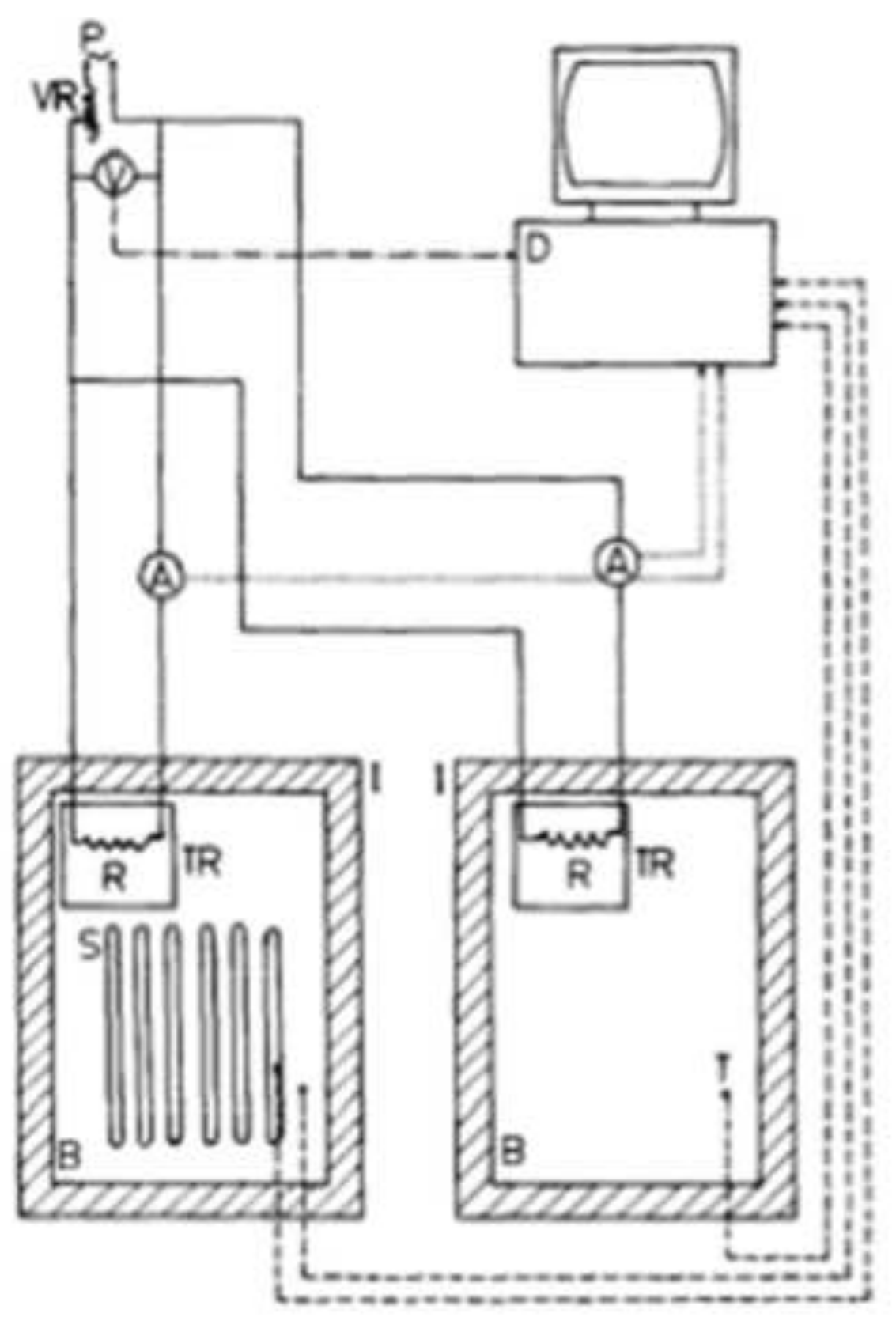

Fig. 6 


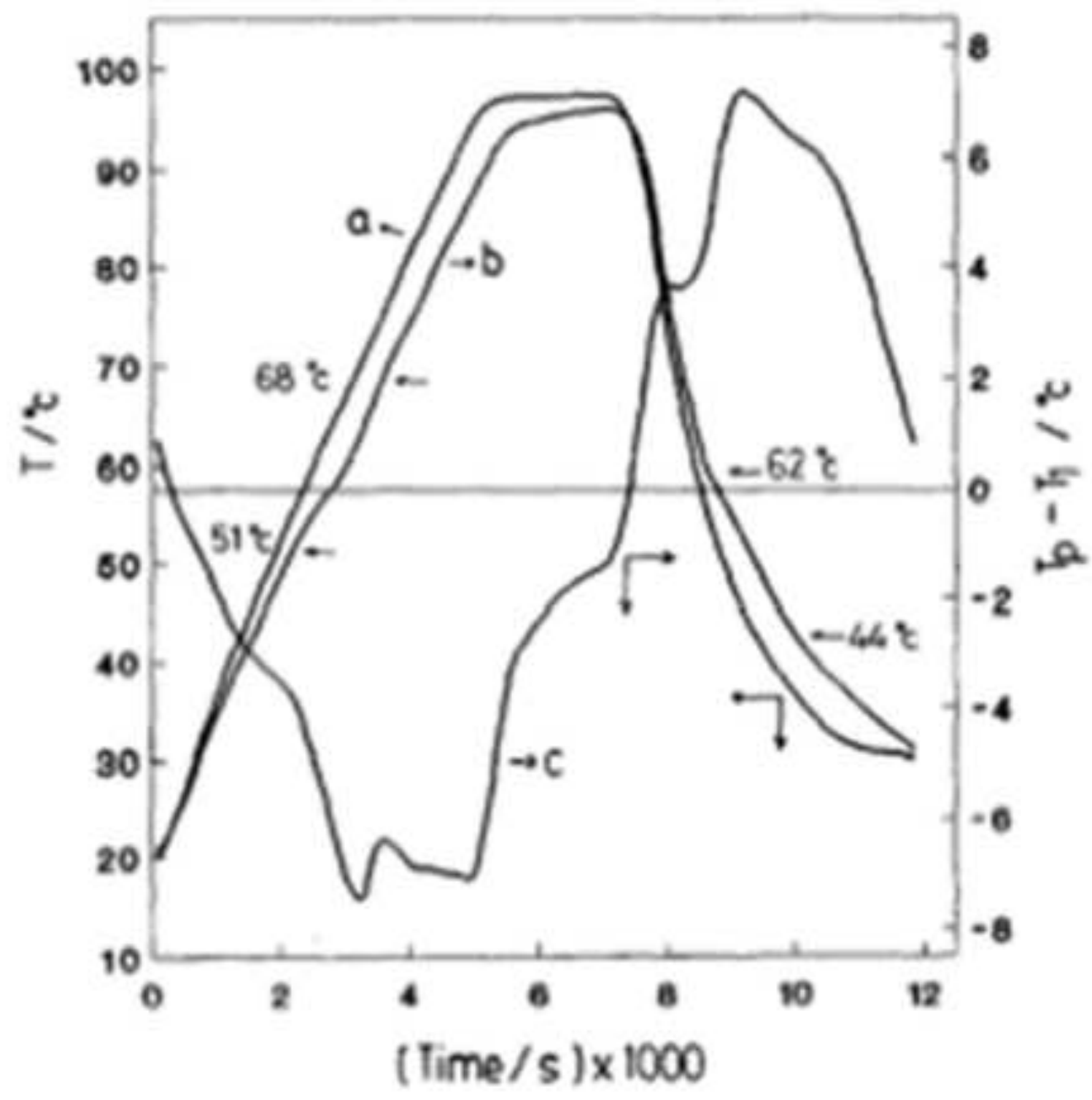

Fig. 7 
Click here to download high resolution image

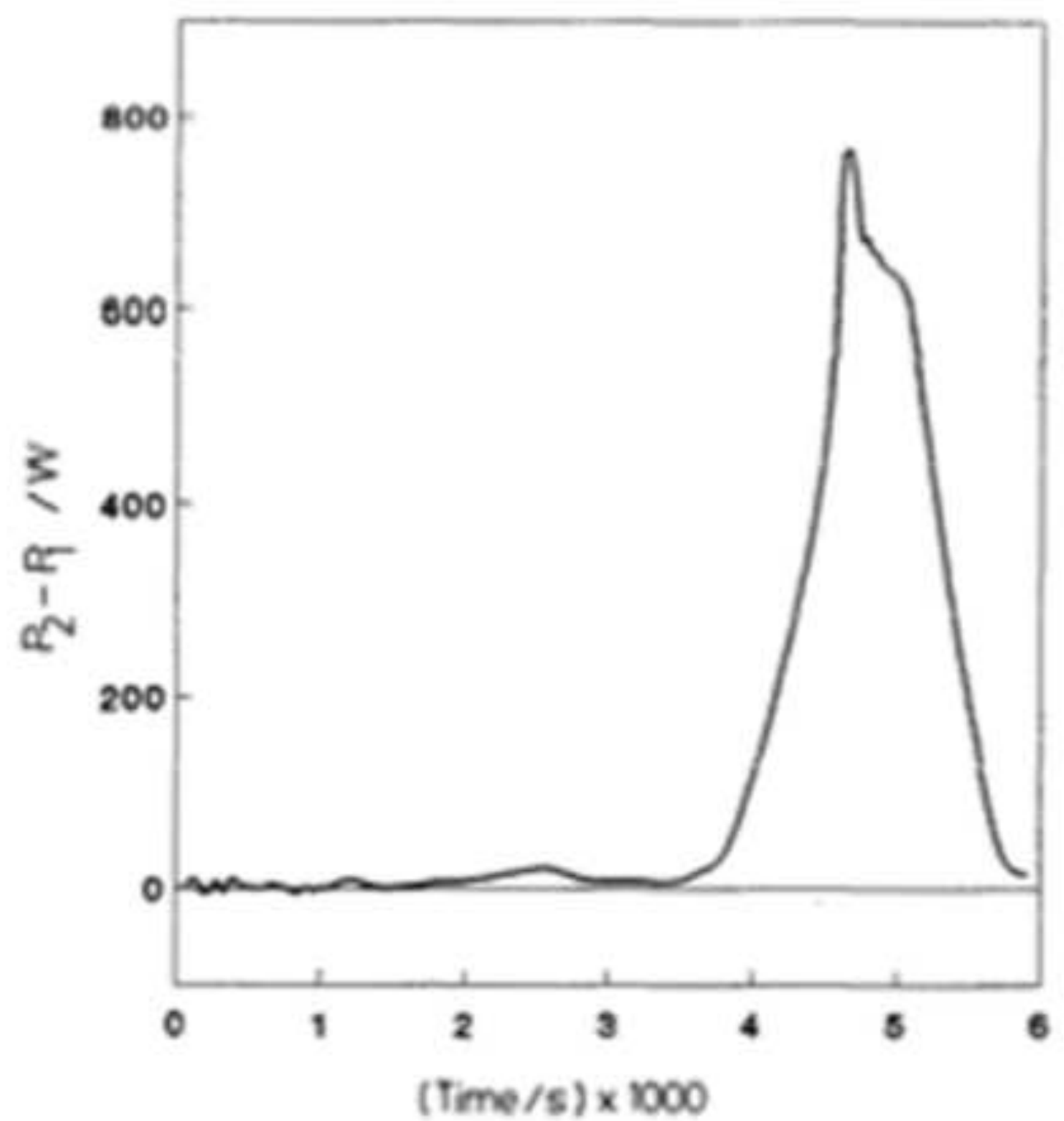

Fig. 8 

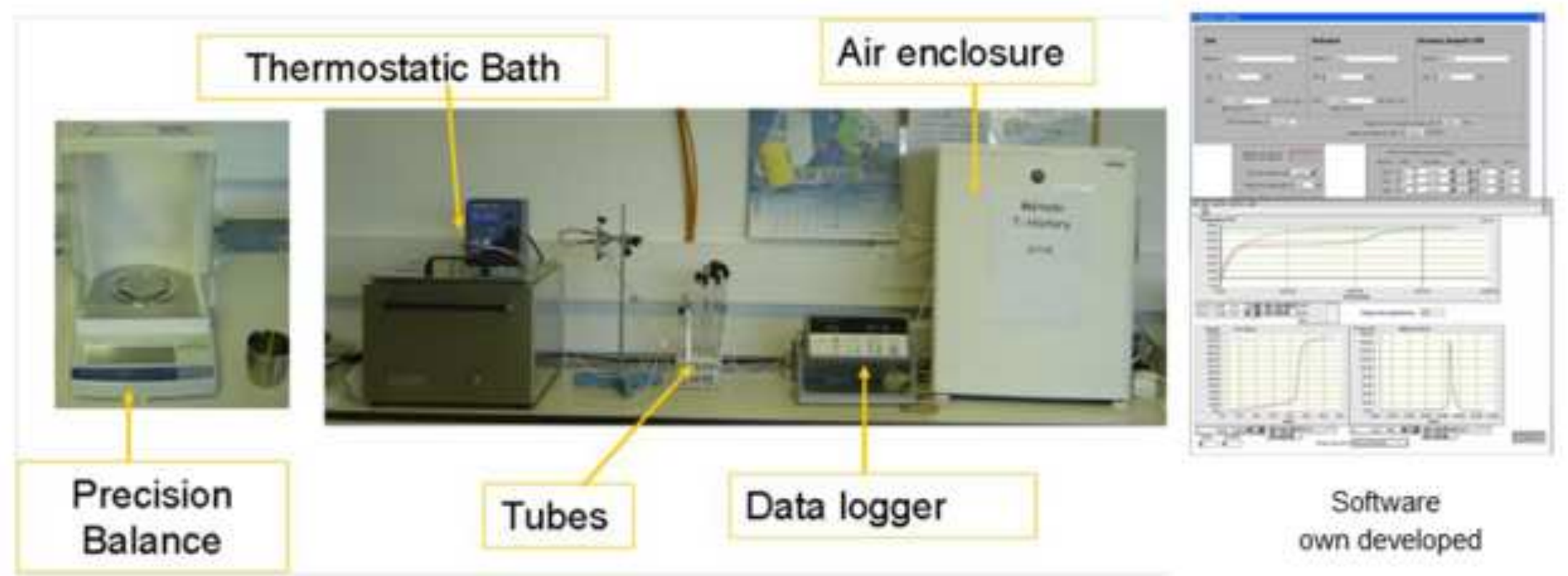

Fig. 9

\section{Fig.}


Click here to download high resolution image
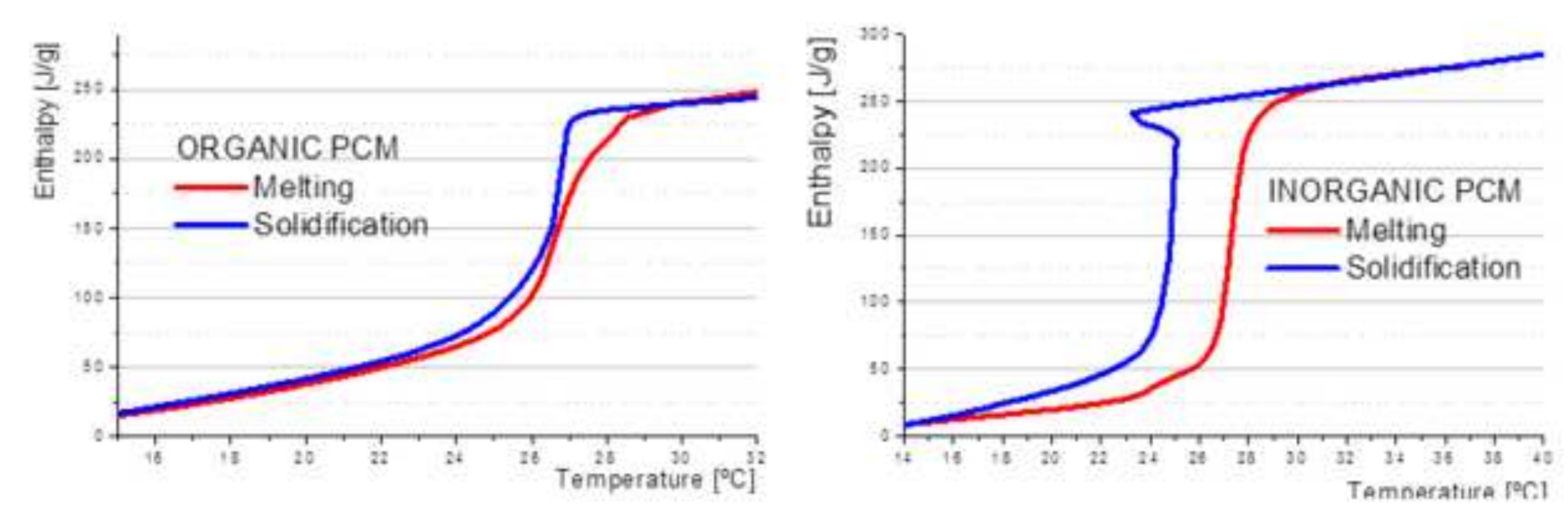

Fig. 10 


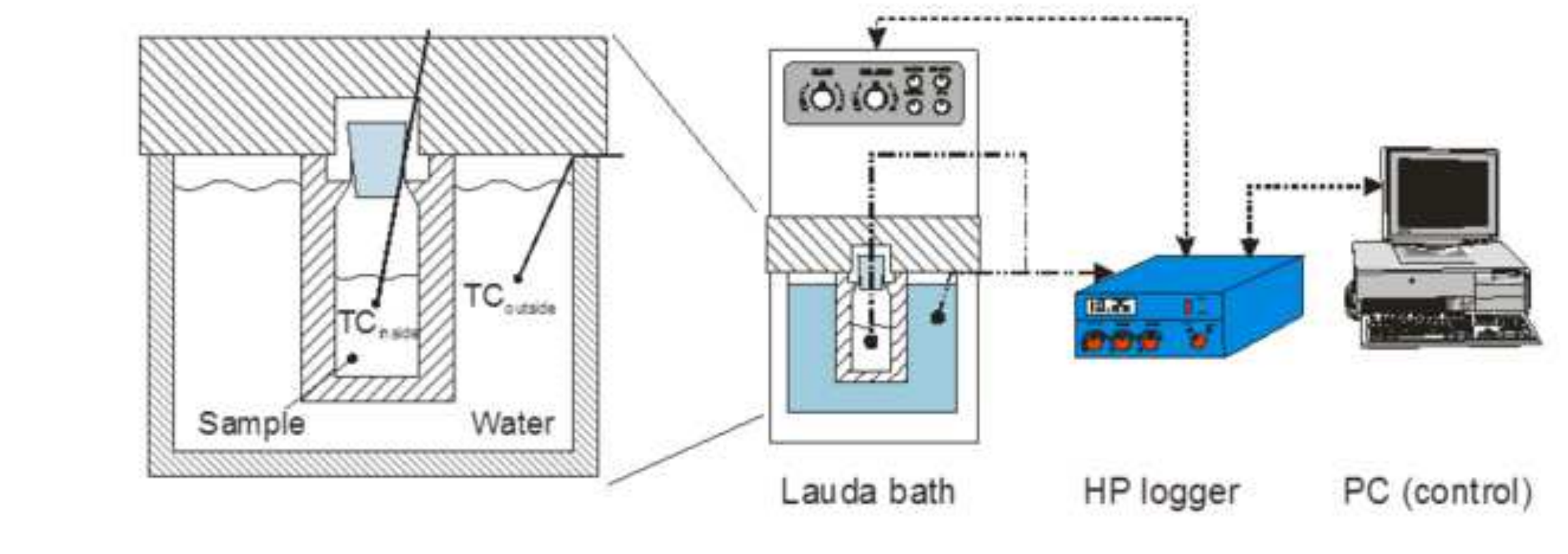

Fig. 11

Fig. 11

11

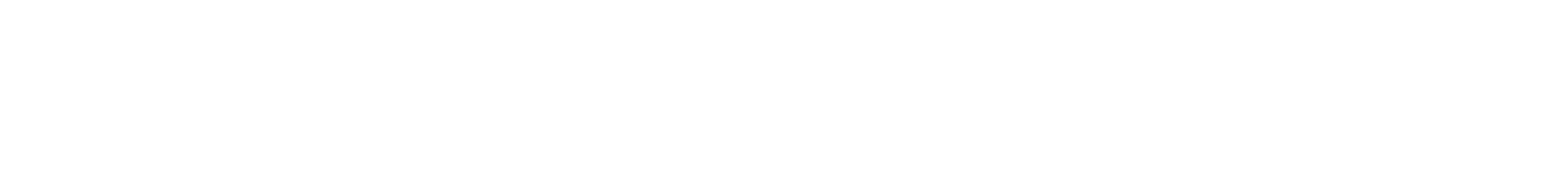

s

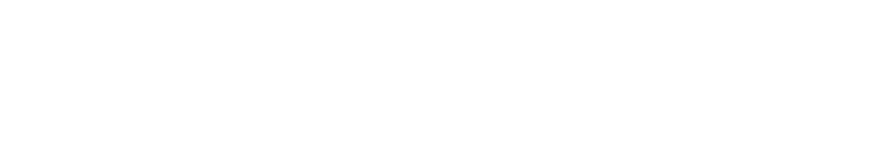

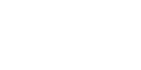

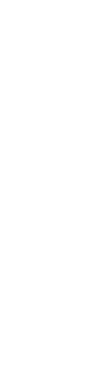

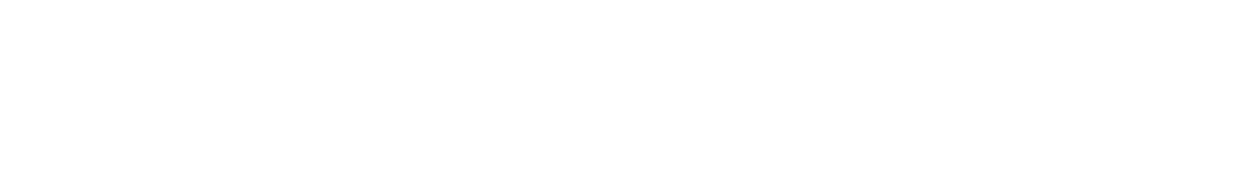

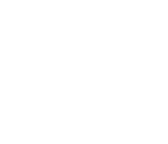




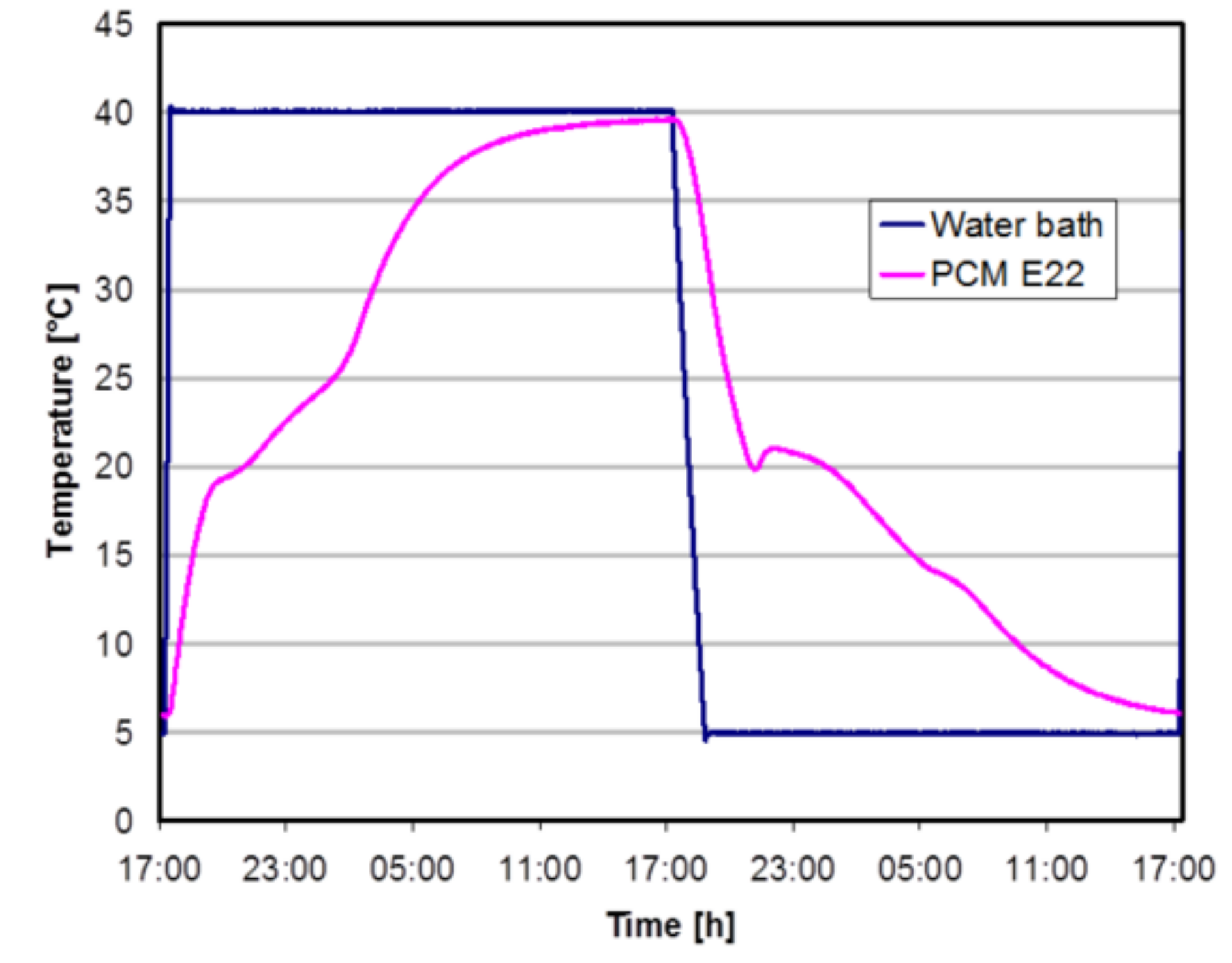

Fig. 13 

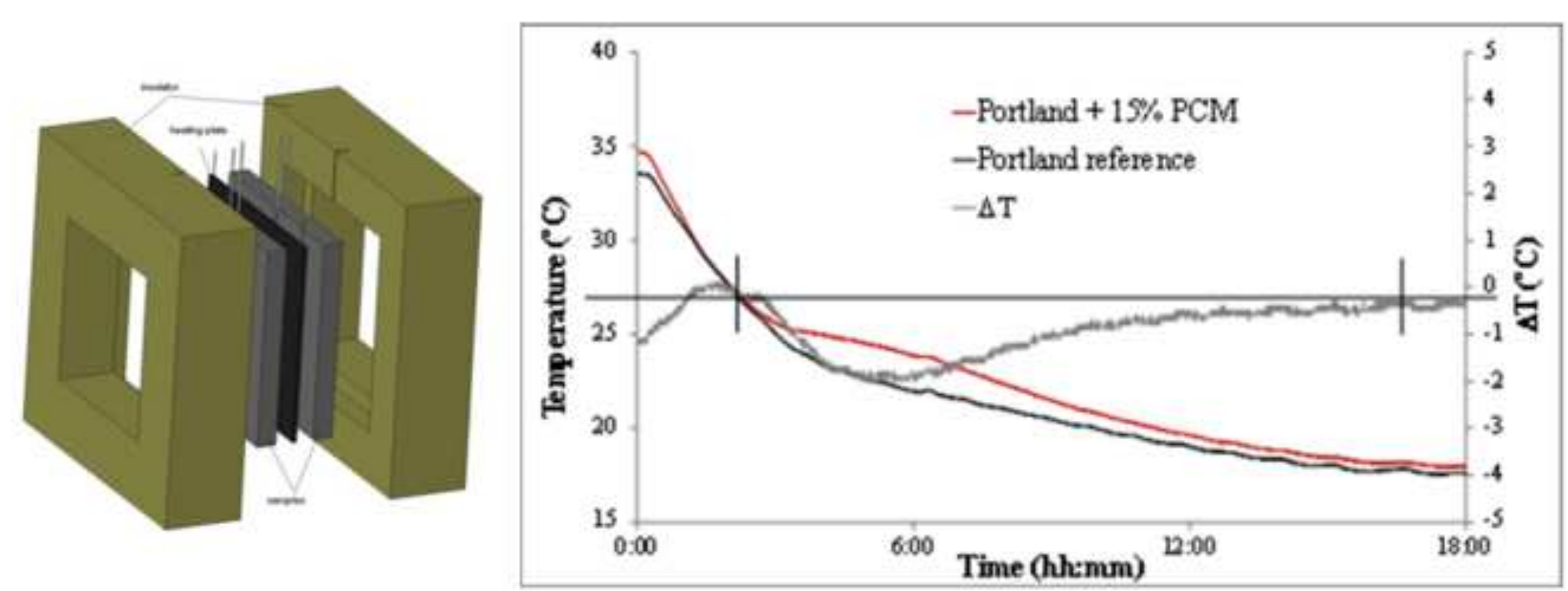

Fig. 14 


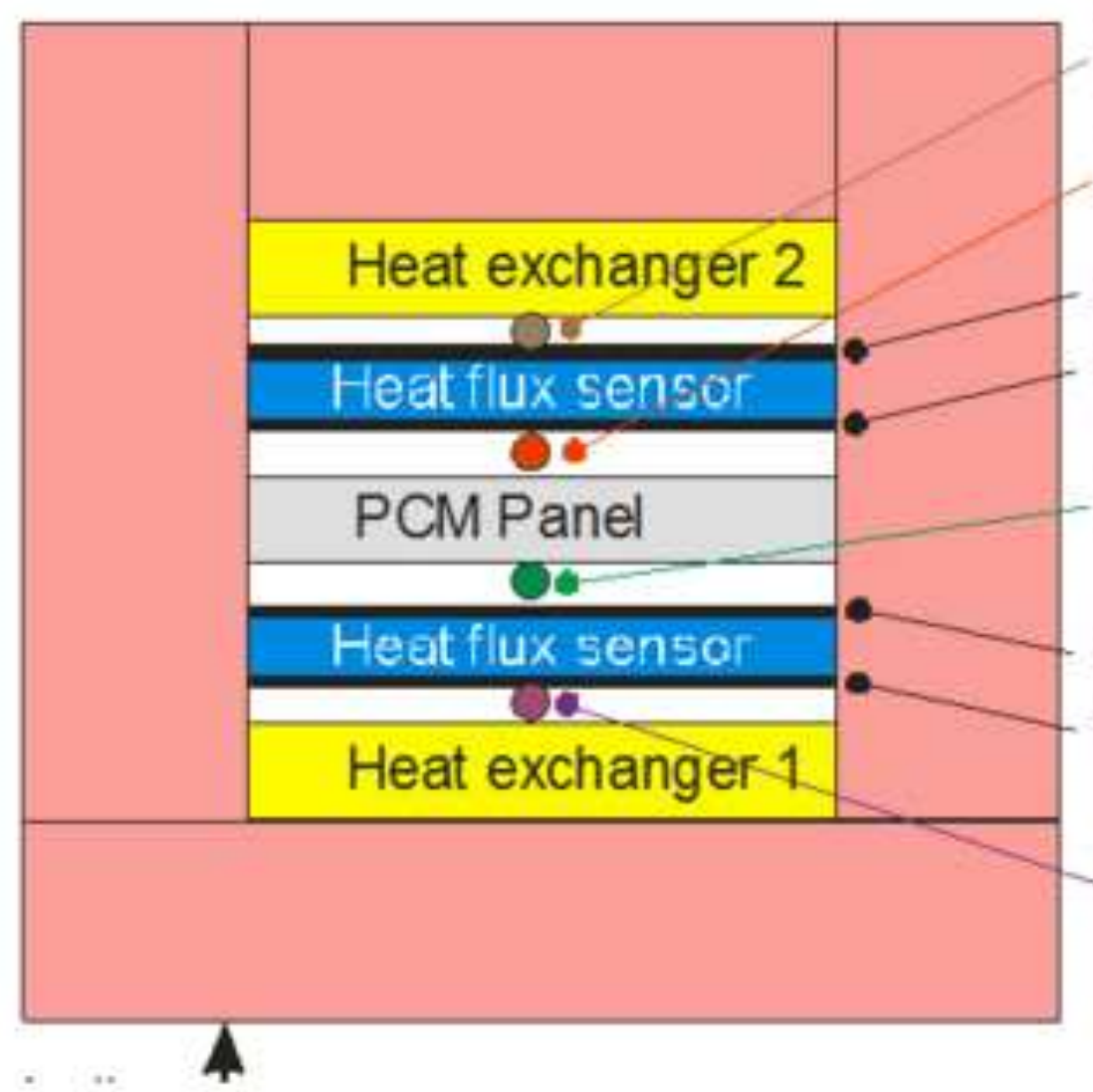

Heat exchanger 2 temperature

Upper surface temperature

HF temperature 1 $\mathrm{HF}$ temperature 2

Bottom surface temperature

HF temperature 4 HF temperature 3

Heat exchanger 1 temperature

Fig. 15 
Figure
Click here to download high resolution image

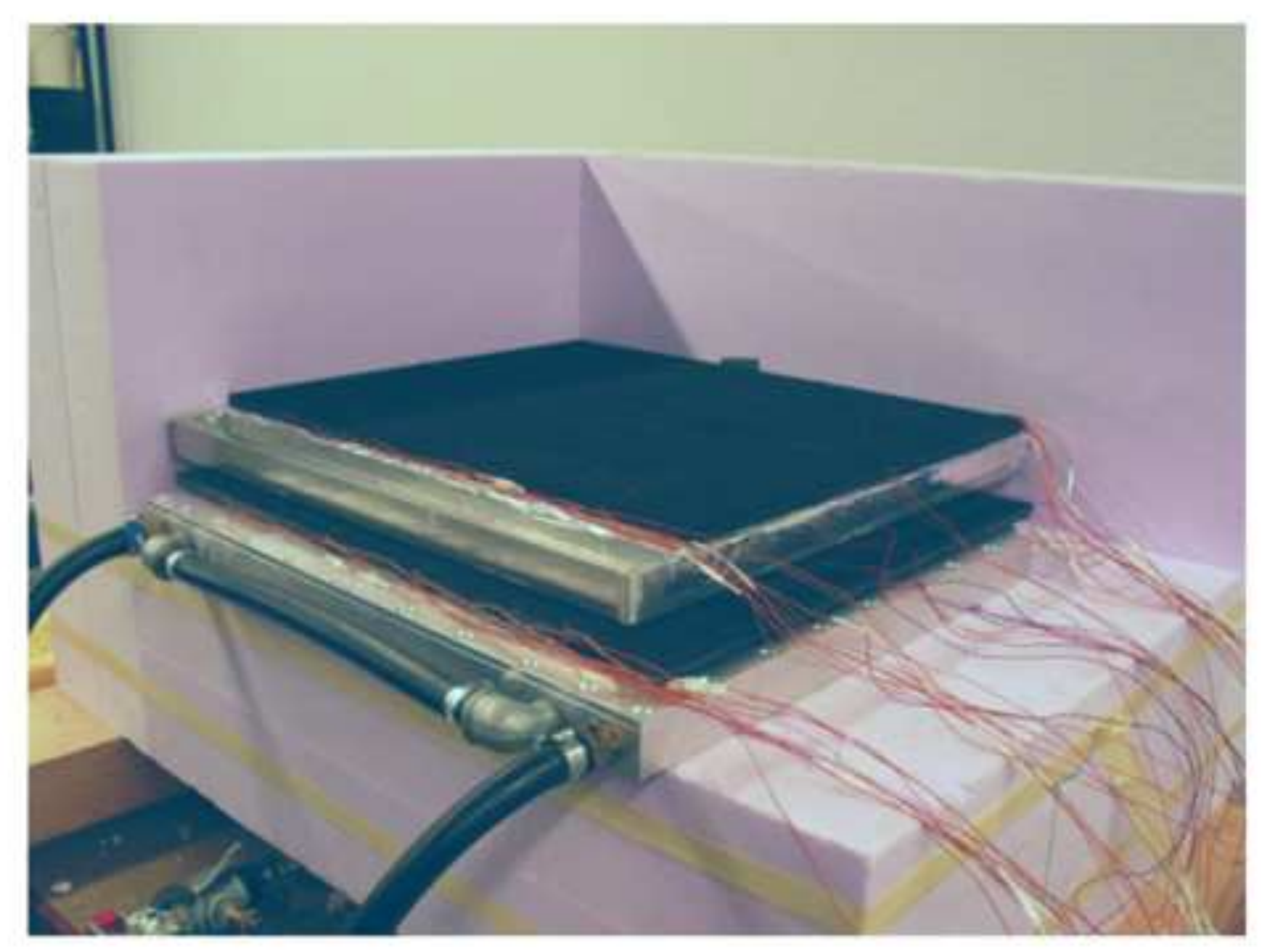

Fig. 16

Click here to download high resolution image

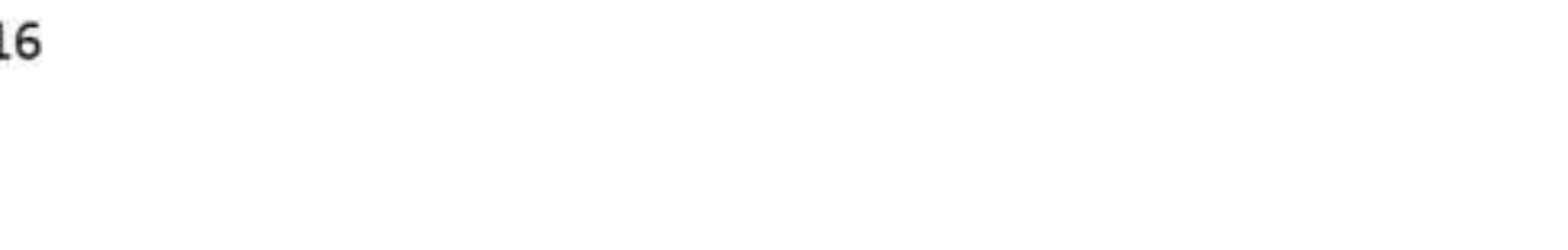

$$
16
$$

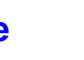
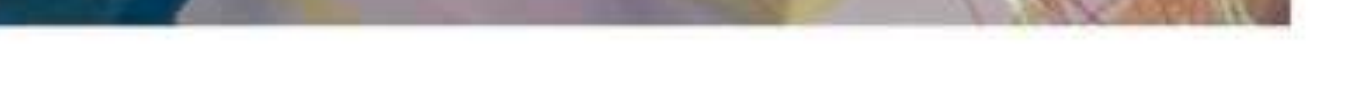


\section{Figure}

Click here to download high resolution image
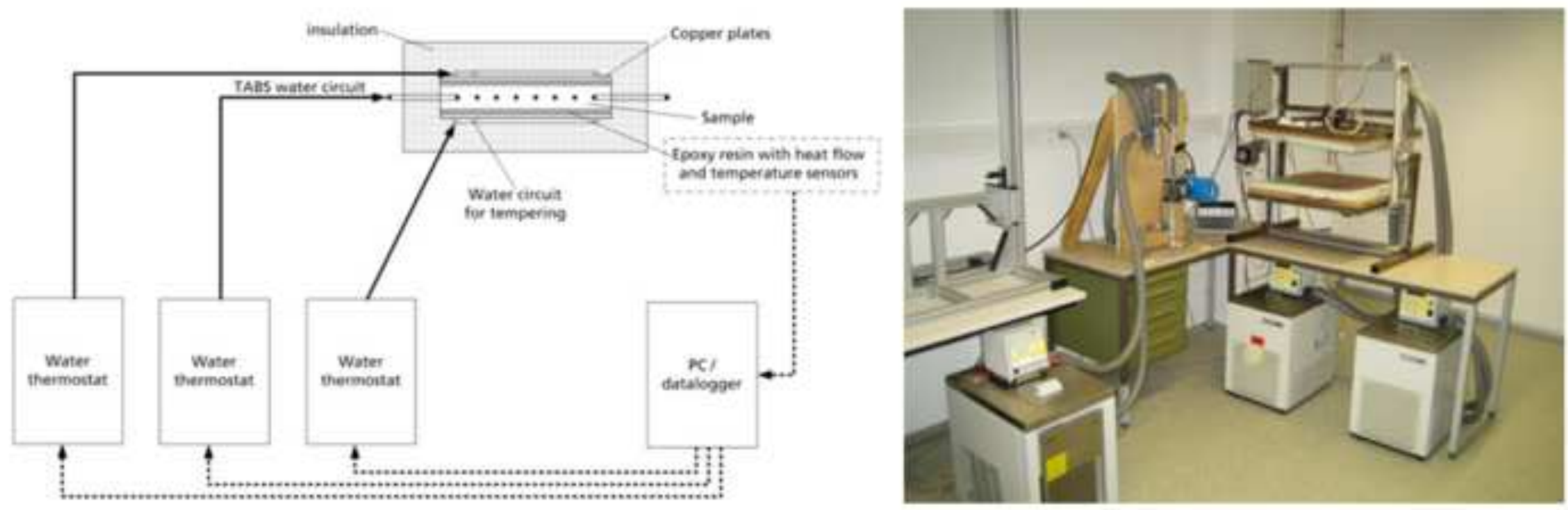

Fig. 17 


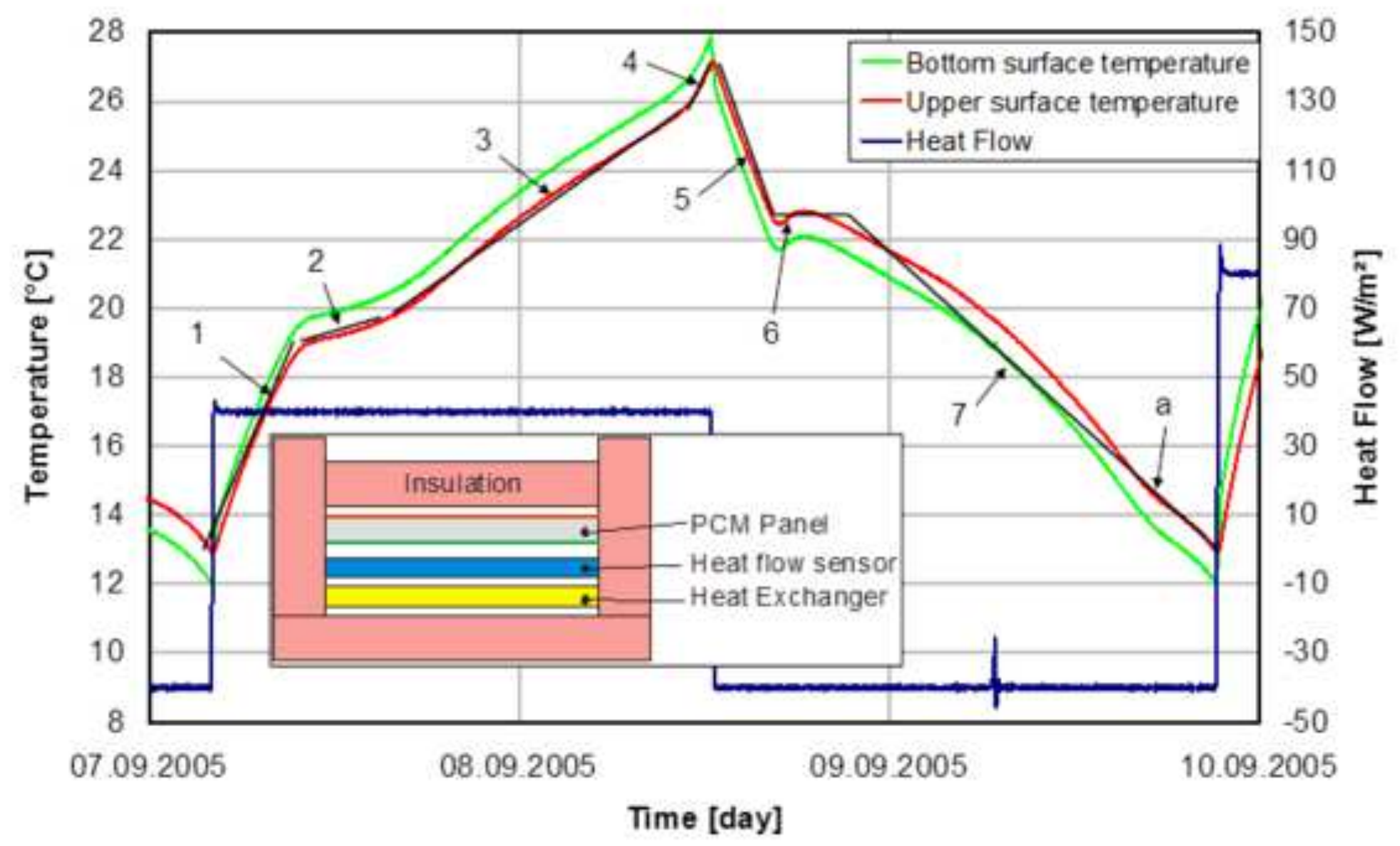

Fig. 18

Figure
Click here to download high resolution imag 


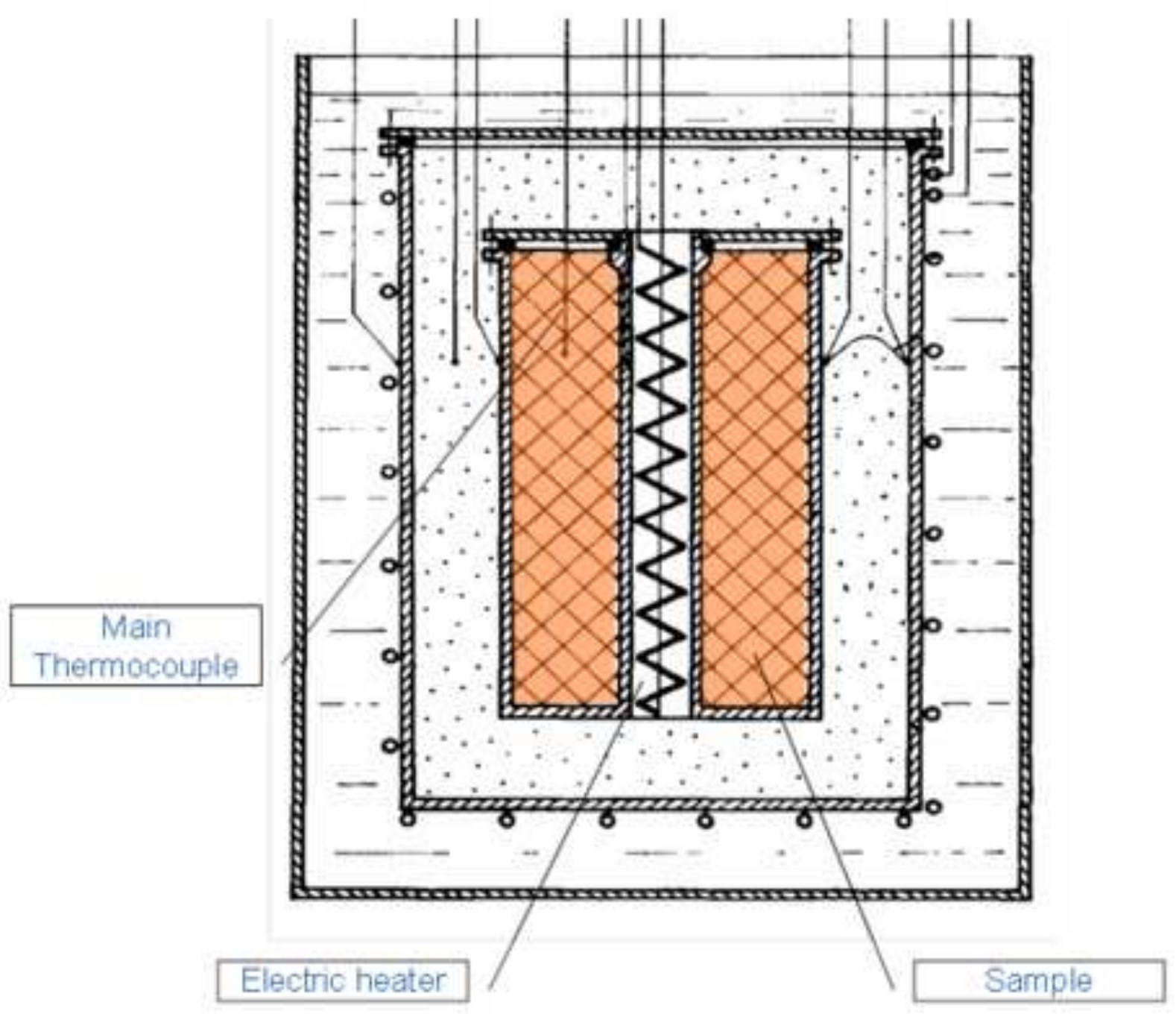

Fig. 19 


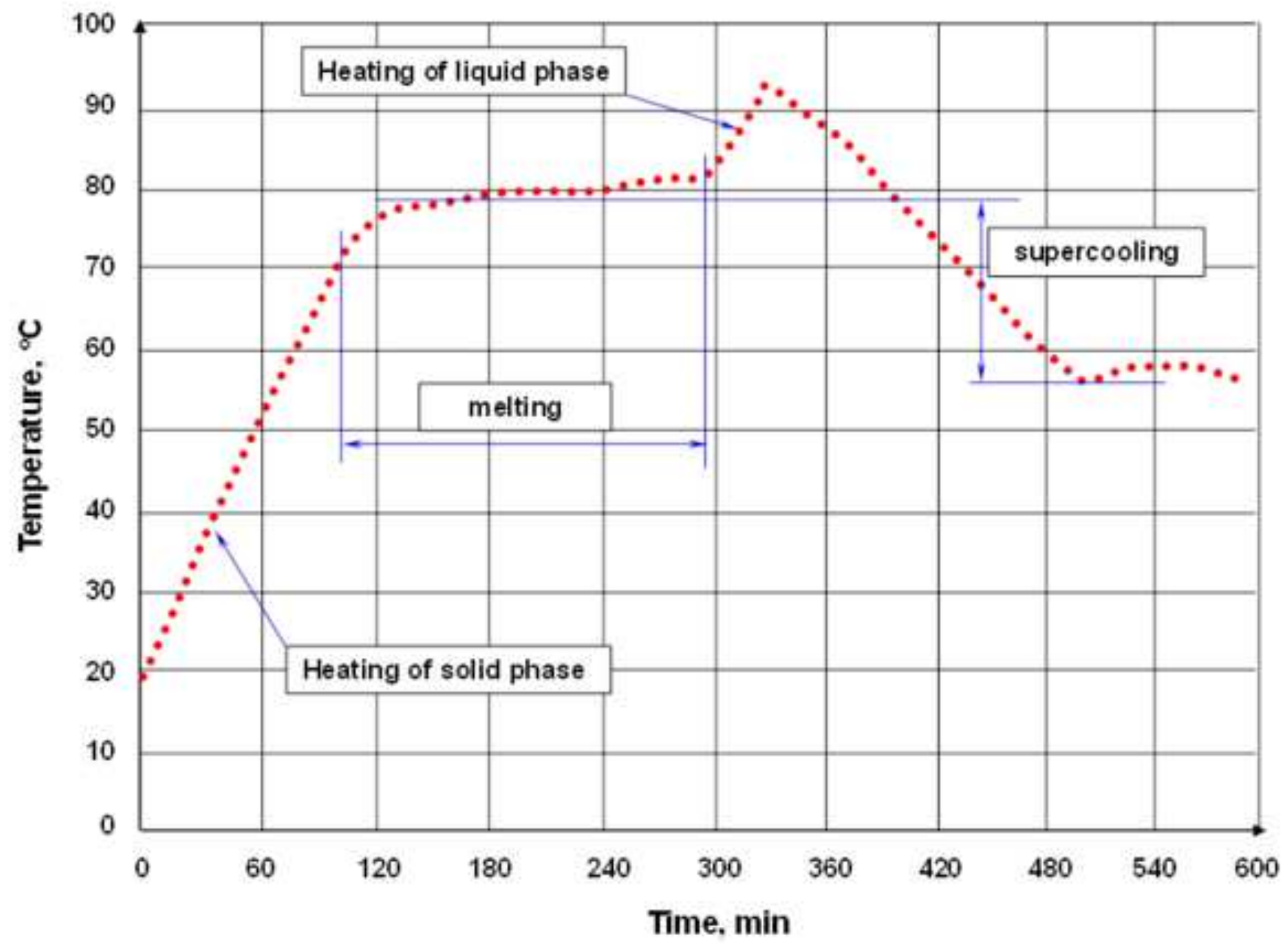

Fig. 20 


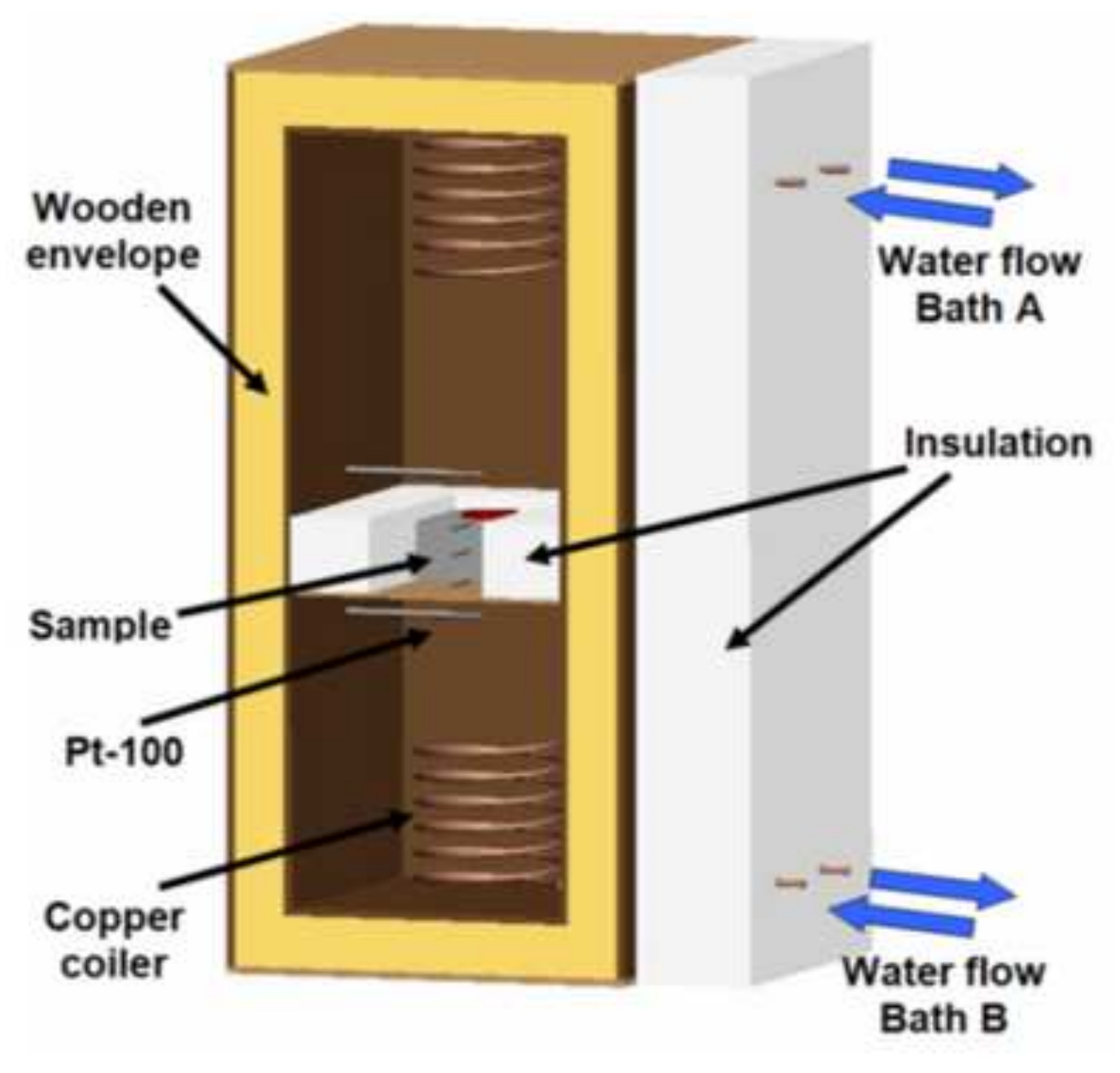

image

Bath B

\footnotetext{
Fig. 21
} 
Click here to download high resolution image

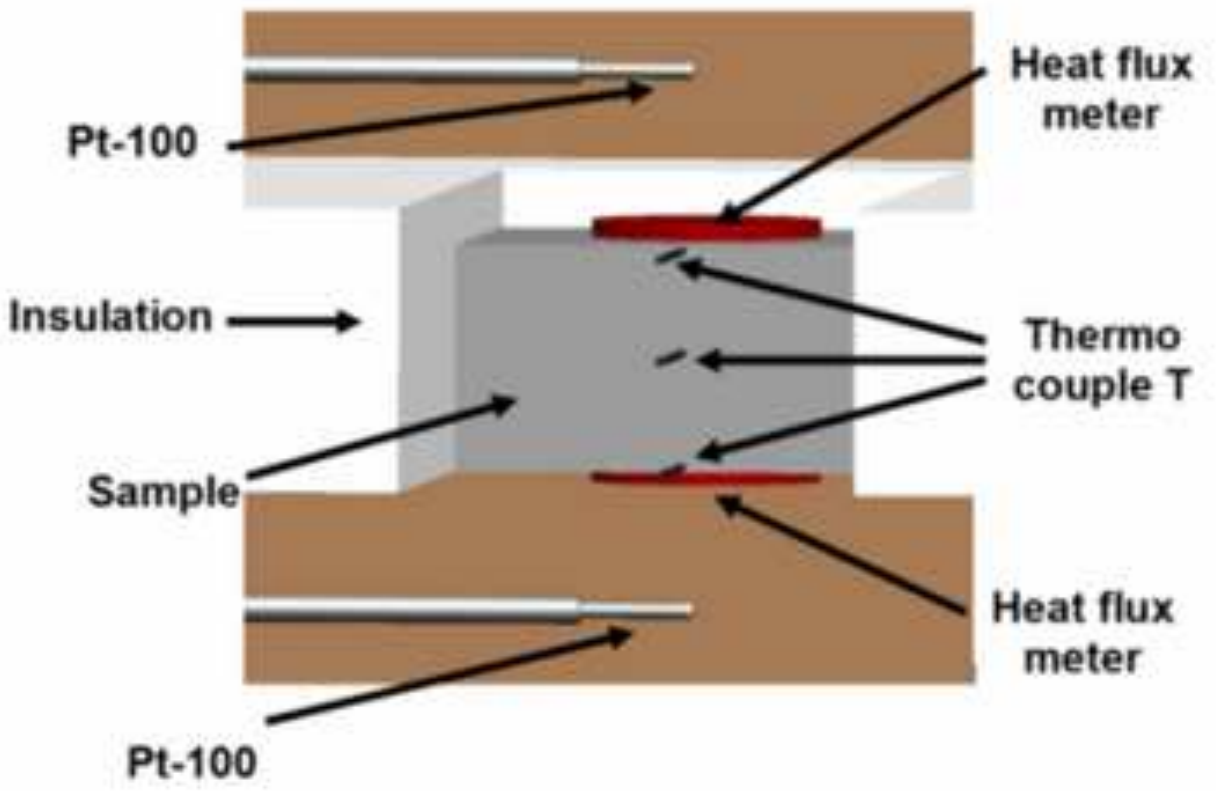

Fig. 22 
Click here to download high resolution image

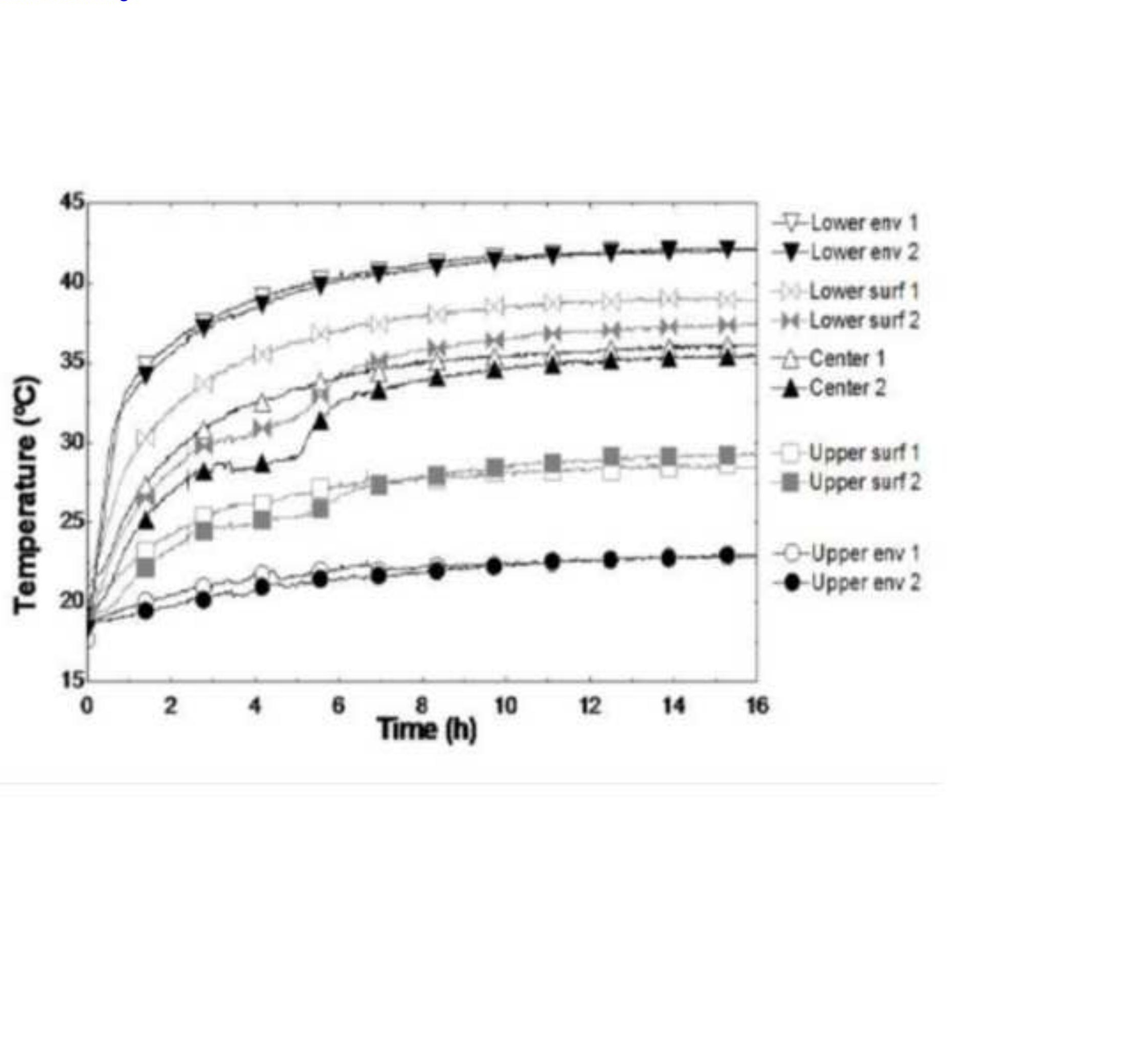

Fig. 23

$$
23
$$

Fig. 23

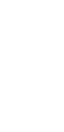
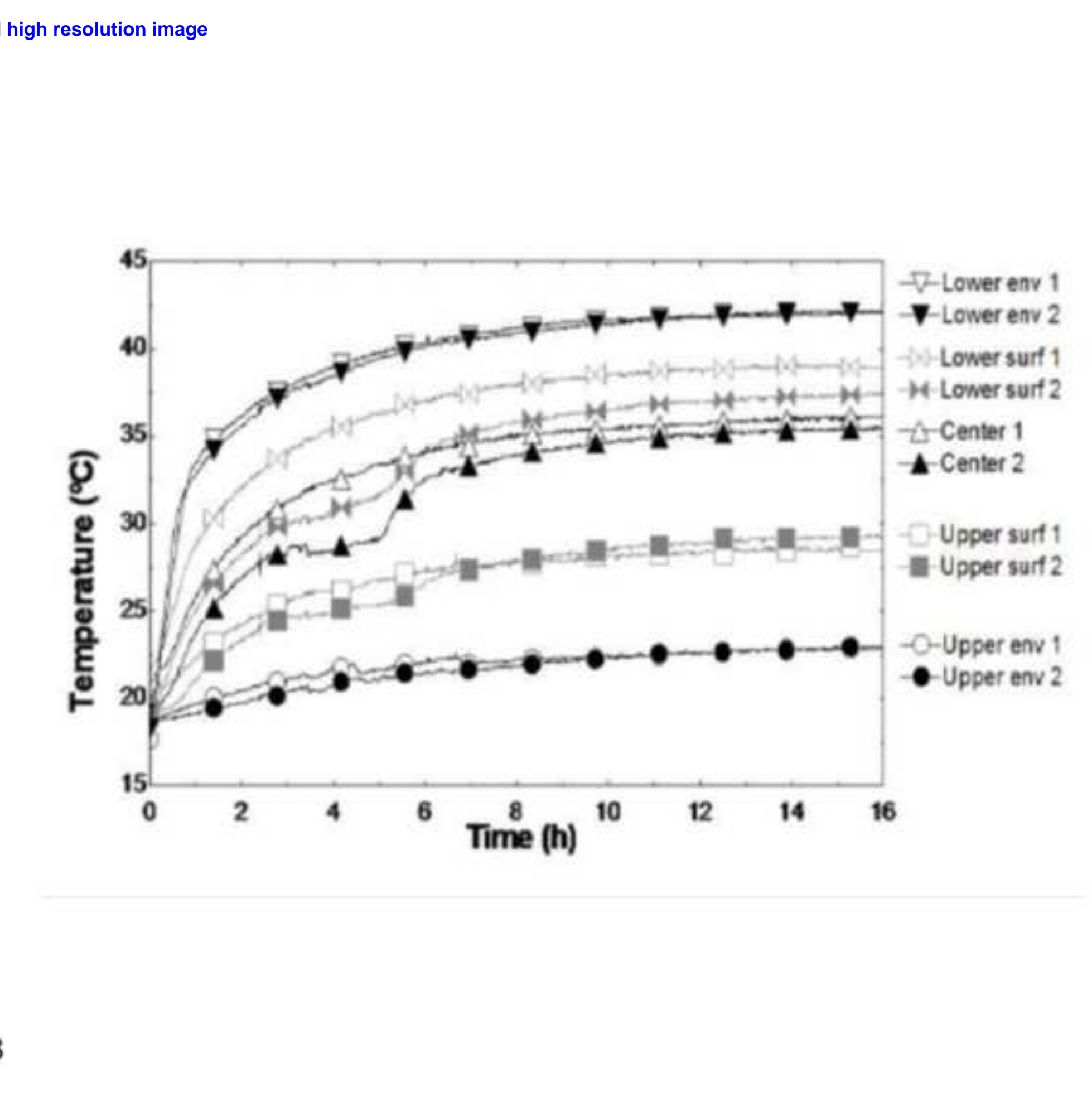

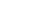

(

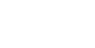

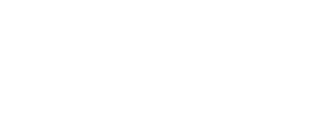
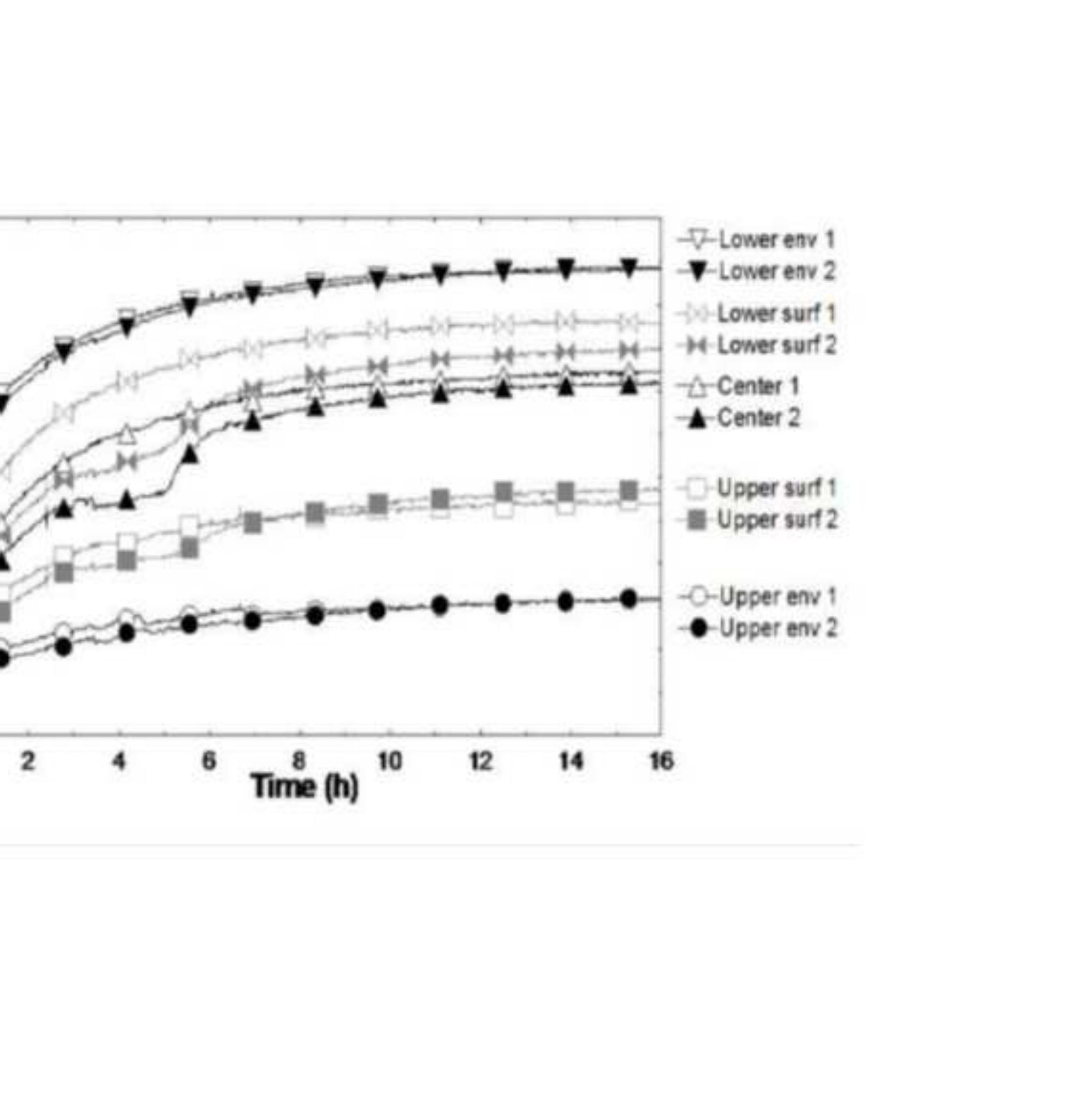

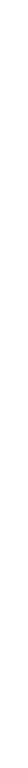

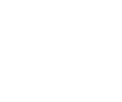

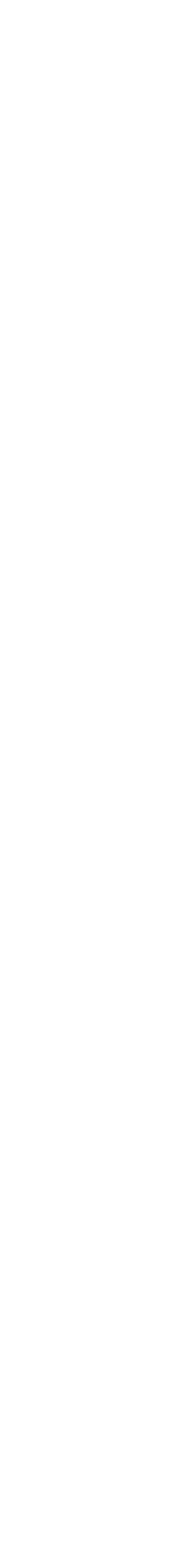

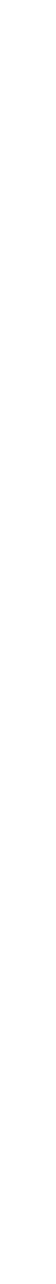




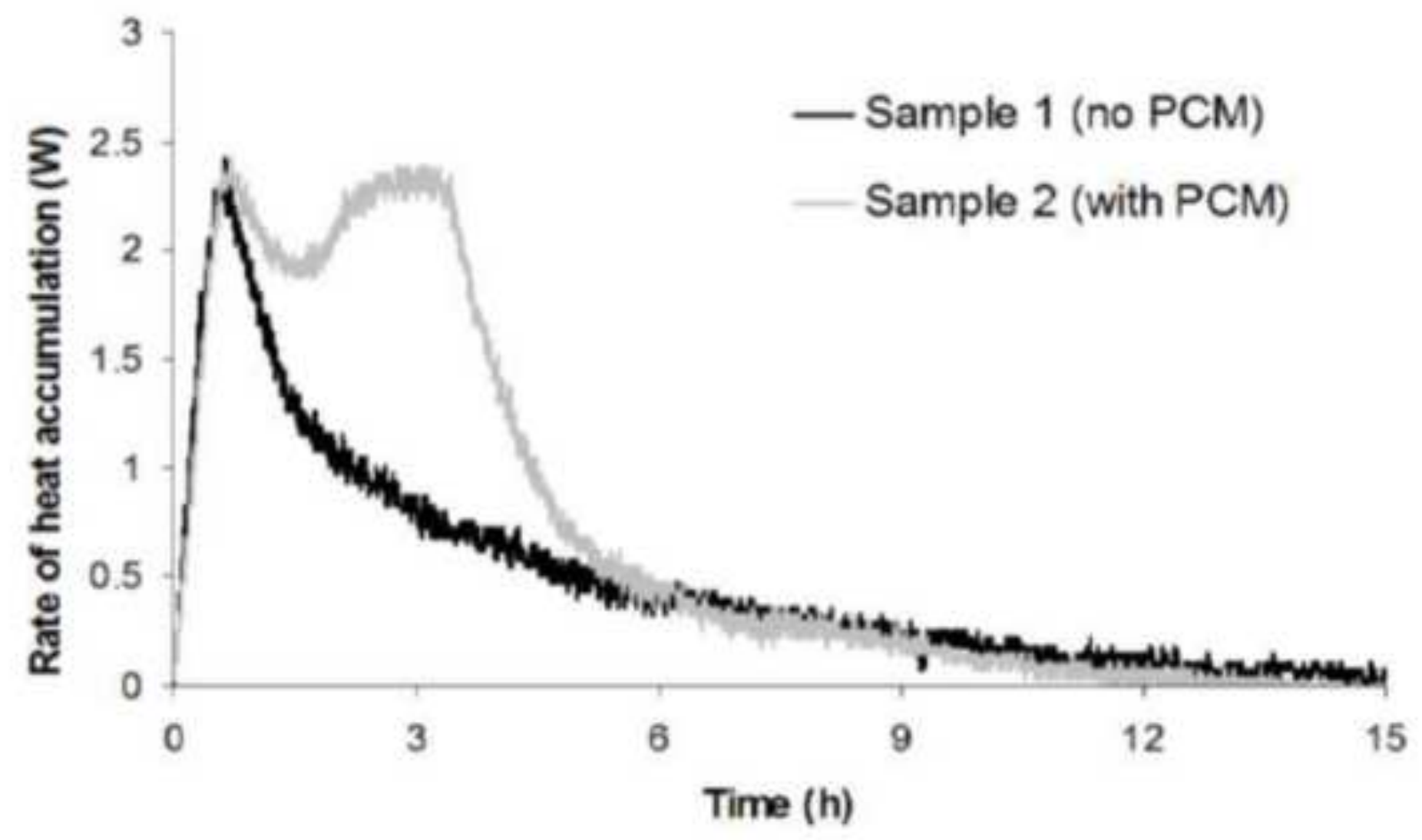

Fig. 24 


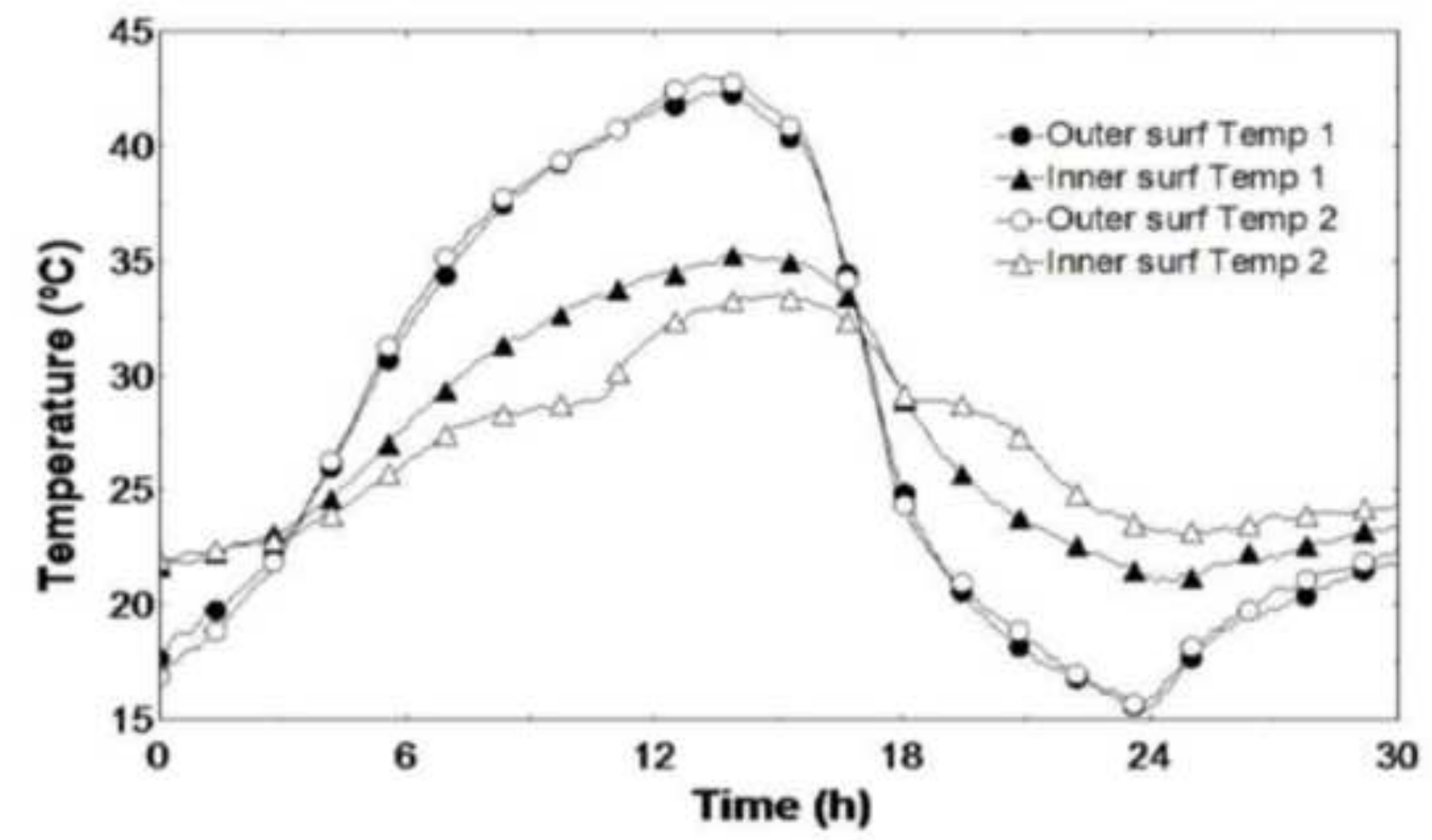

Fig. 25

Figure
Click here to download high resolution imag

$$
25
$$


Click here to download high resolution image

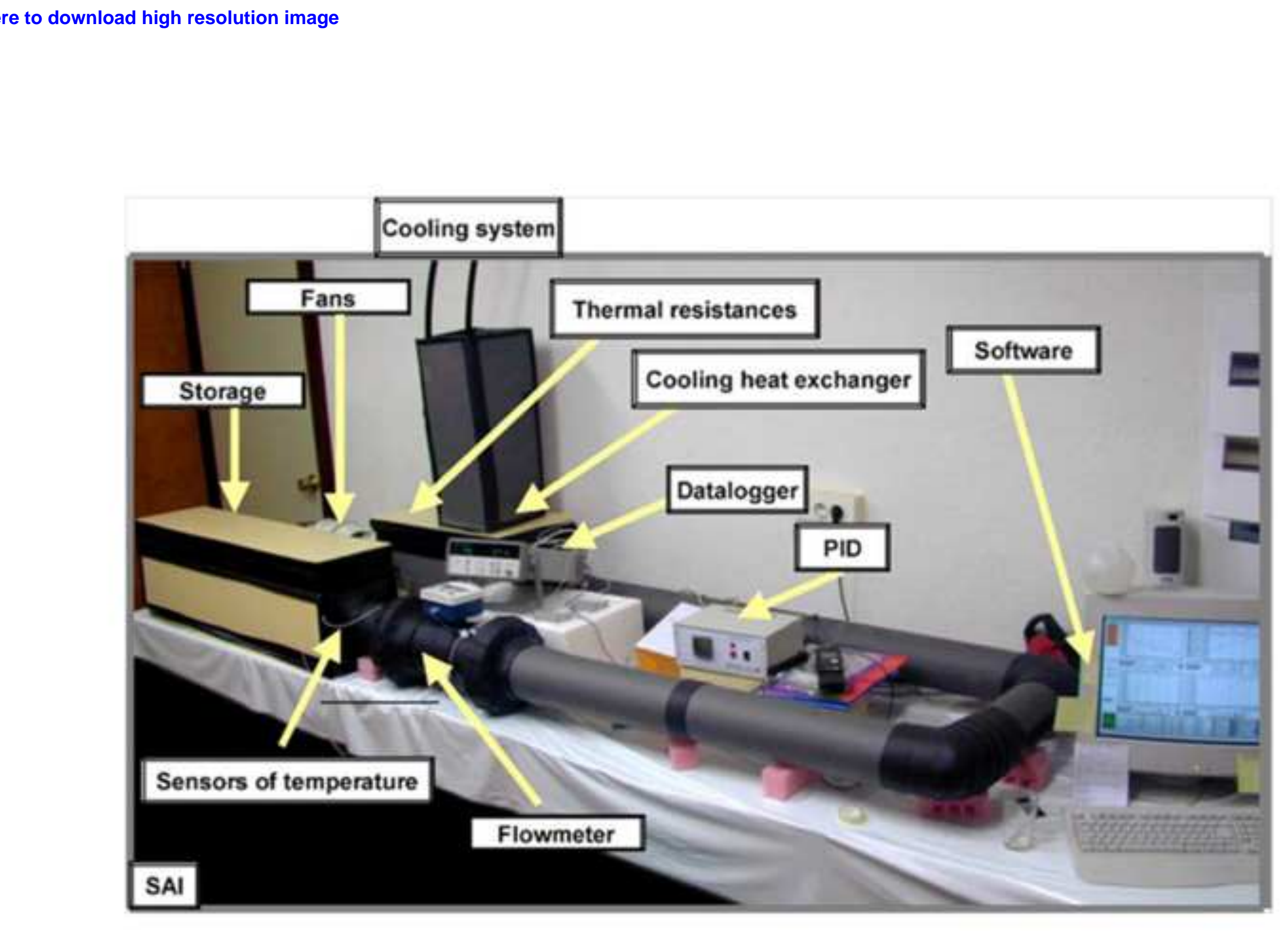

Fig. 27

7


Click here to download high resolution image

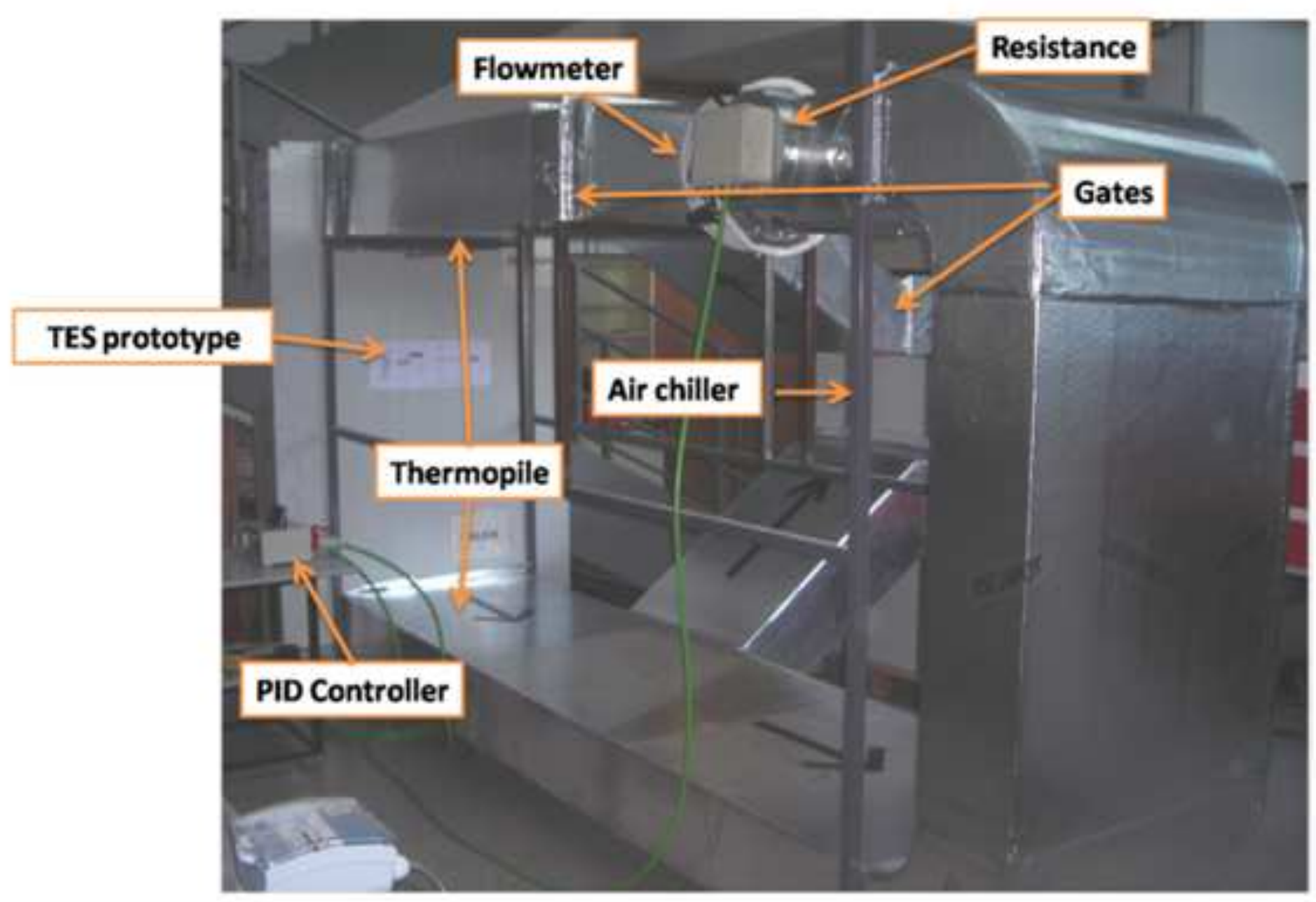

Fig. 28

PID Controller

$$
8
$$

\section{Fig. 28}


Figure
Click here to download high resolution image
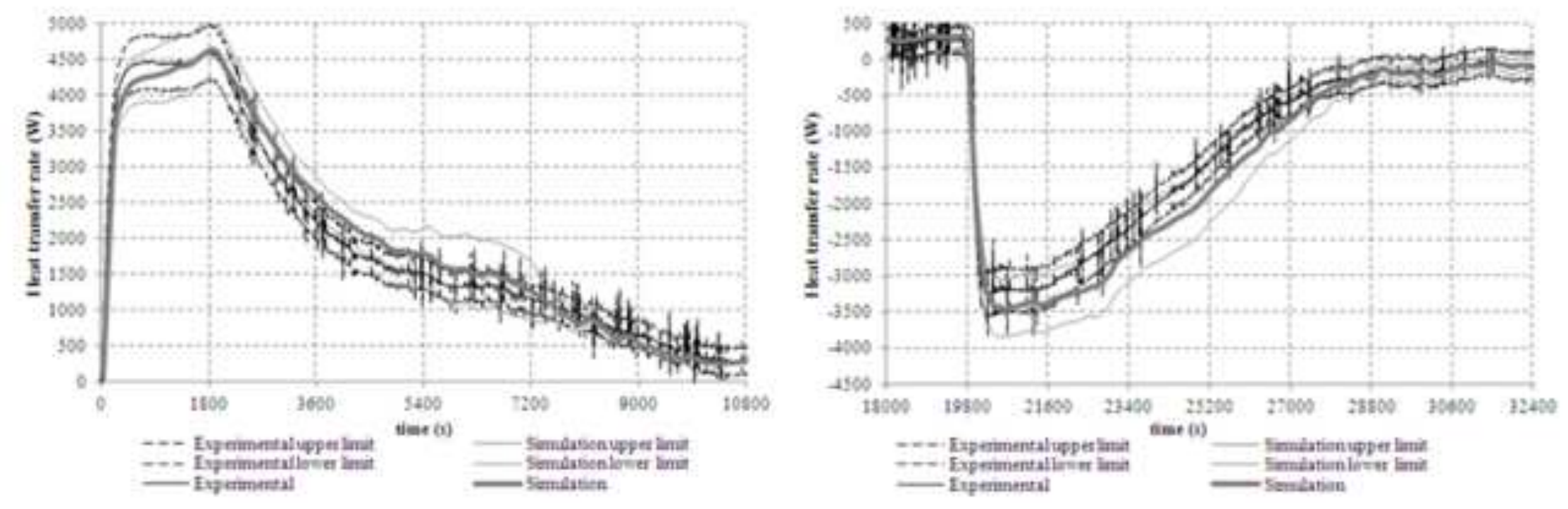

Fig. 29 
Figure
Click here to download high resolution image

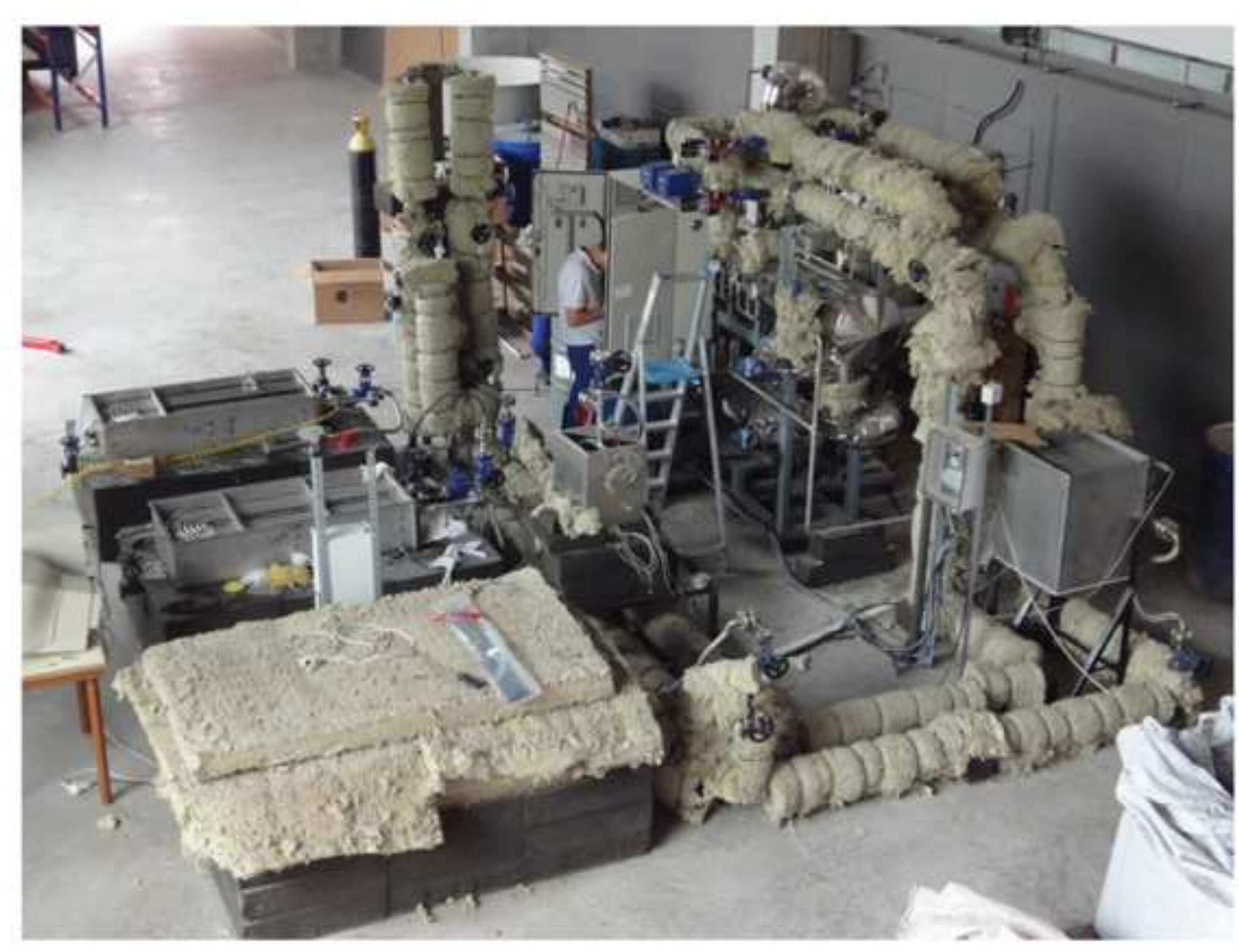

Fig. 30 


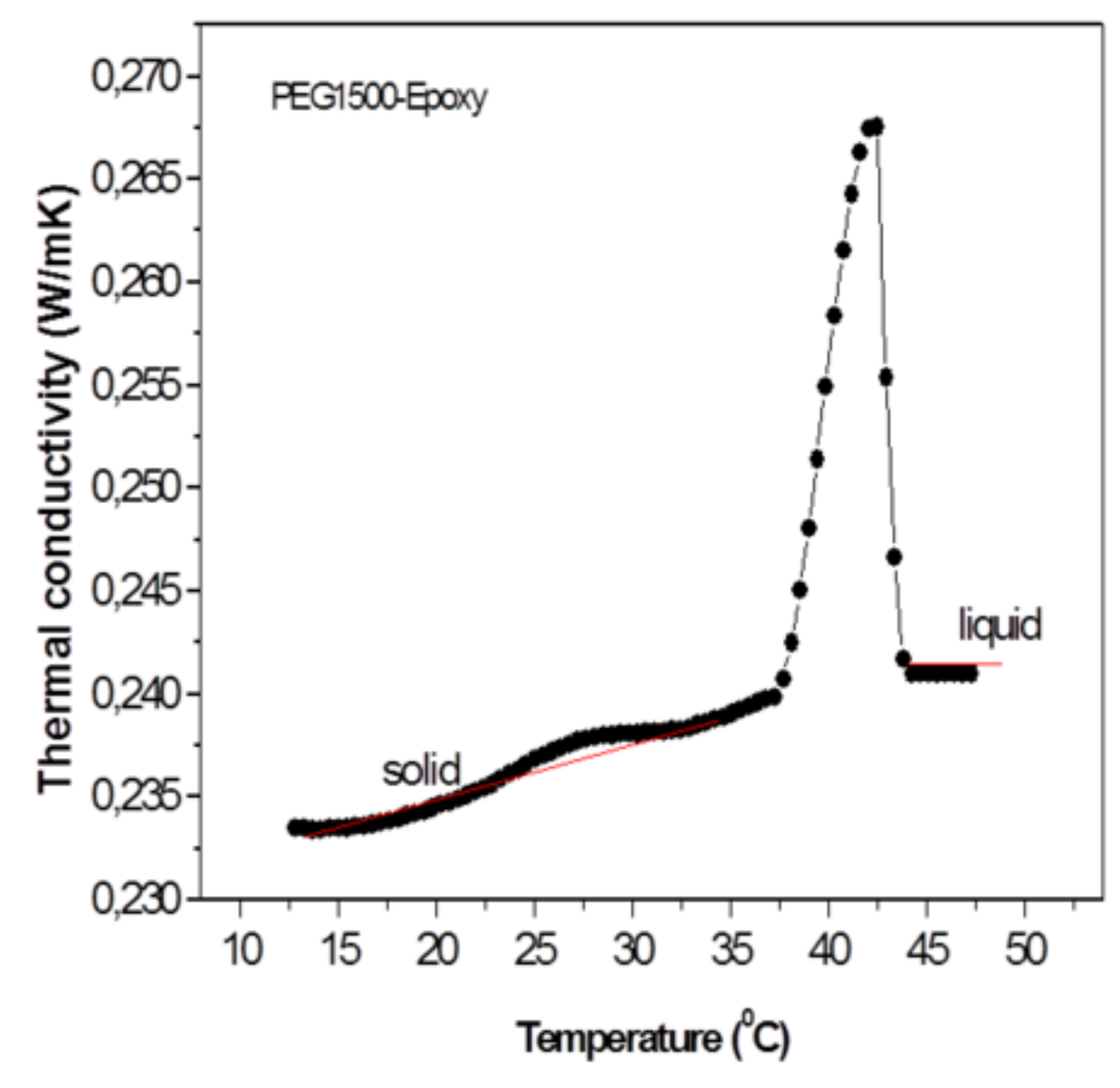

Fig. 32

Fig. 32

. 


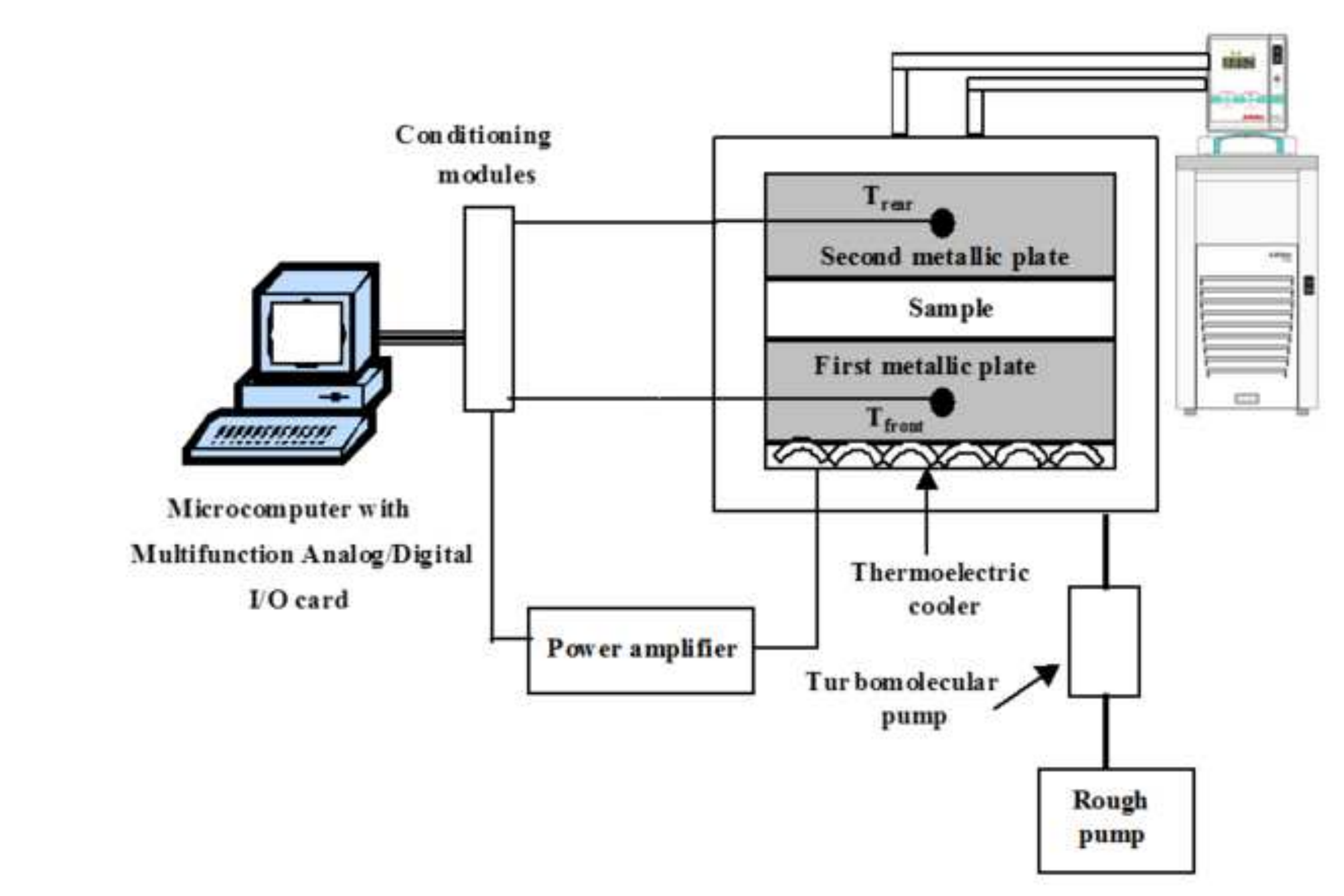

Fig. 33 I/O card

\begin{abstract}
Iultifunction Analog/Digital
\end{abstract}
Fig. 33

33



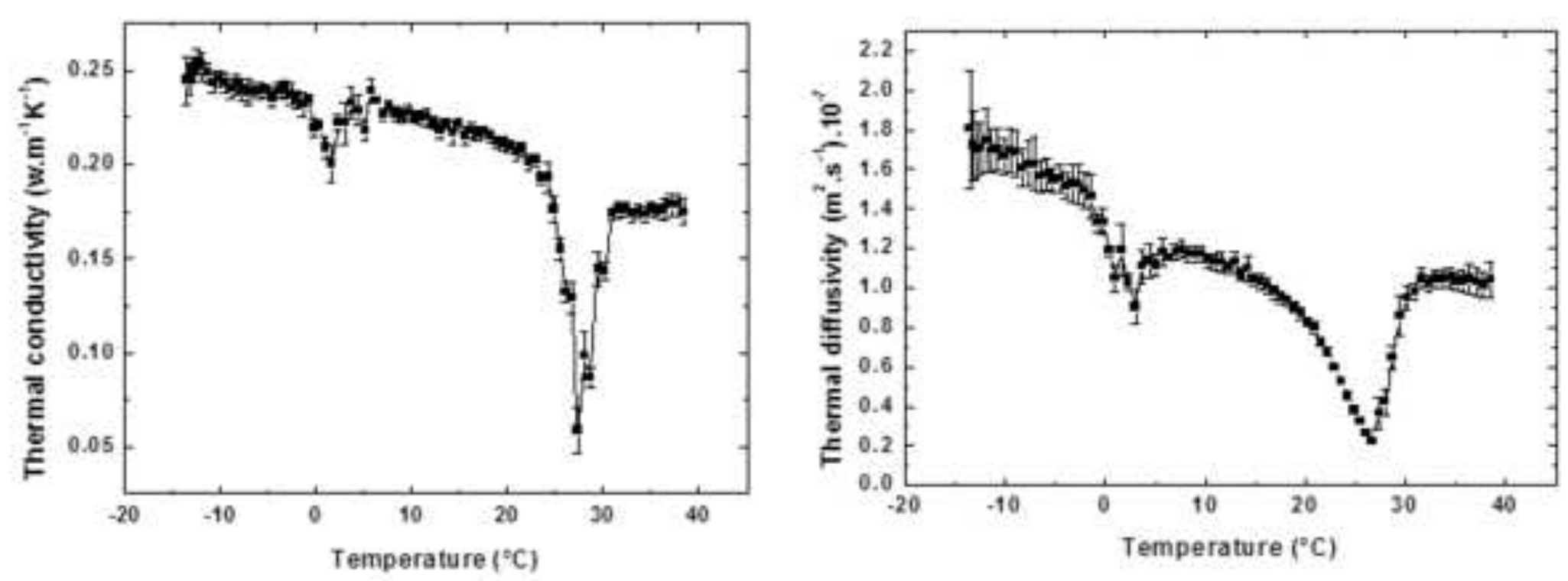

Fig. 34 

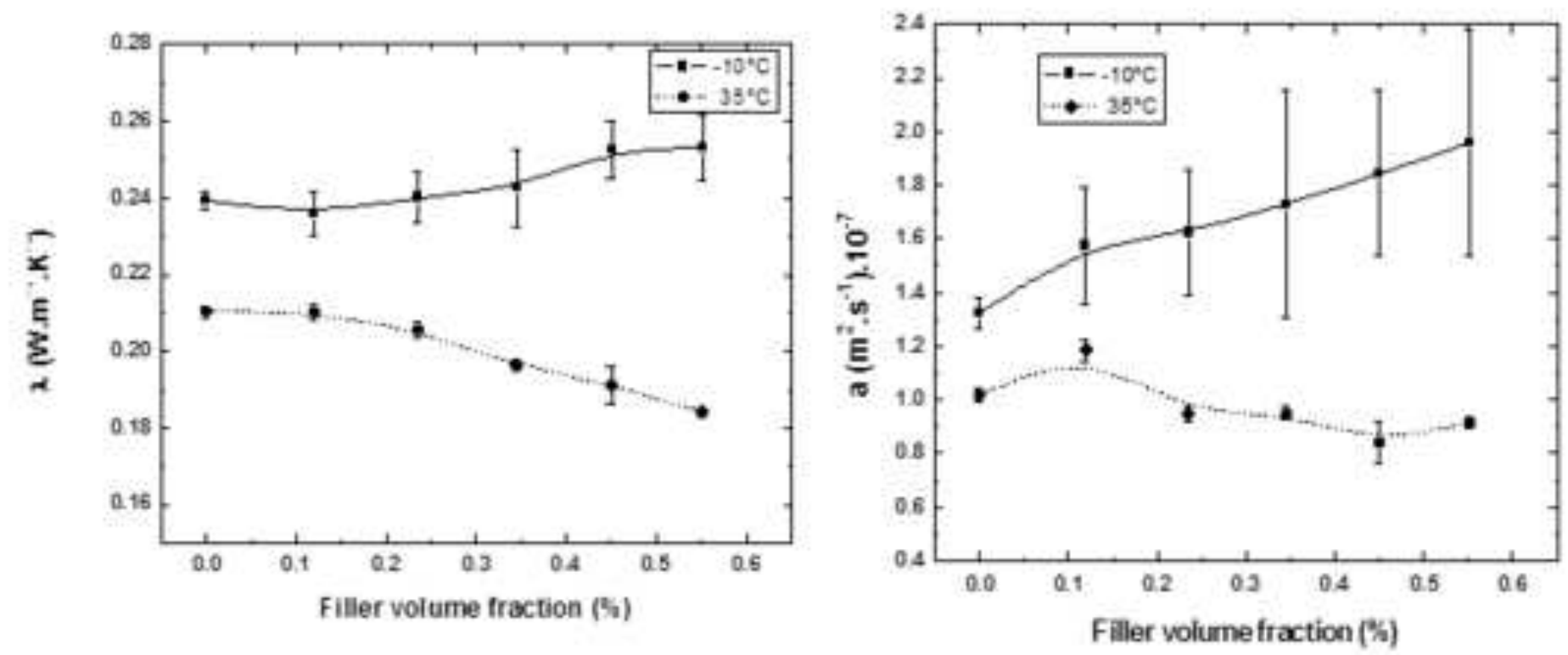

Fig. 35 


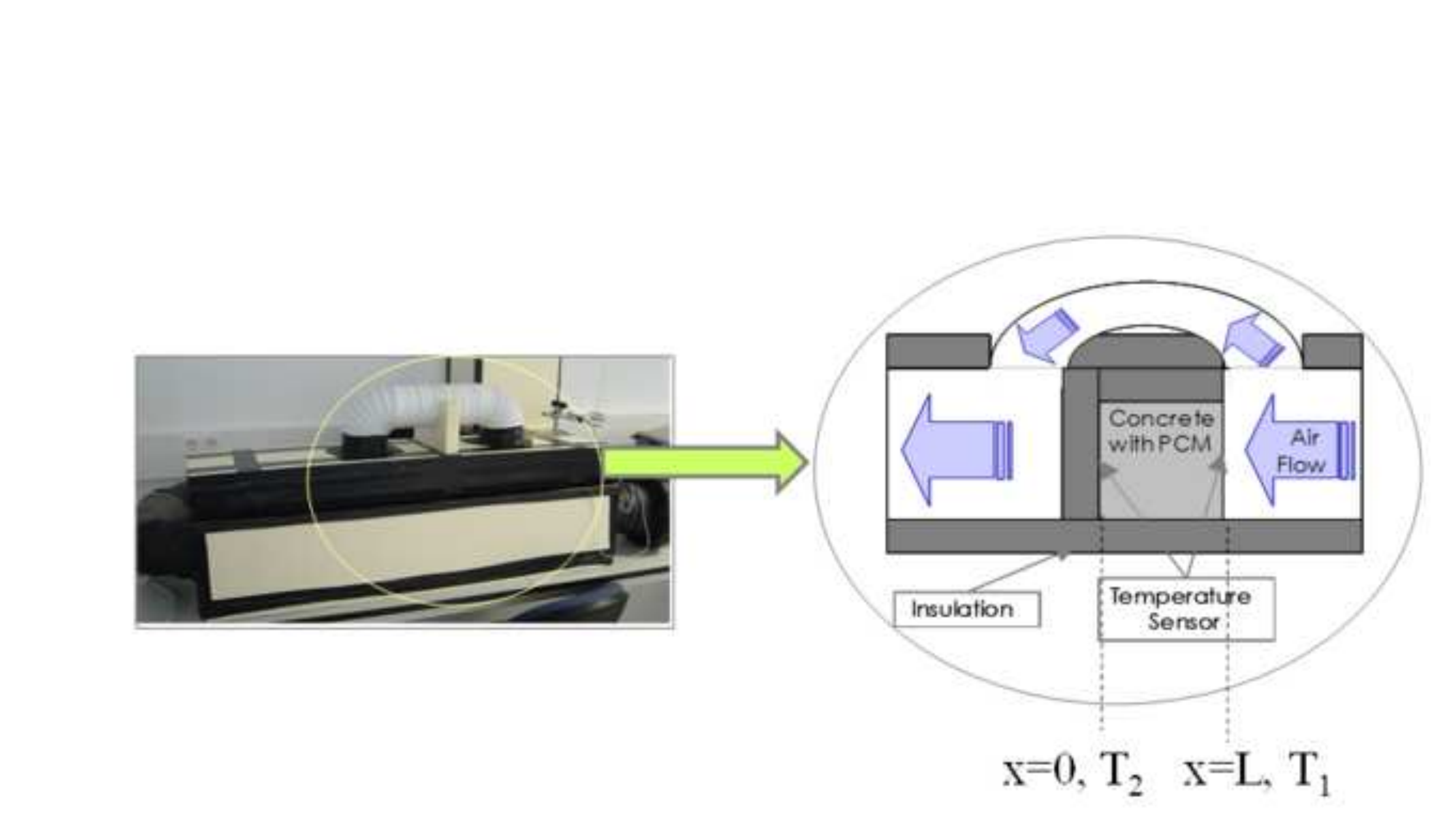

Fig. 36

$\mathrm{x}=0, \mathrm{~T}_{2} \quad \mathrm{x}=\mathrm{L}, \mathrm{T}_{1}$

6

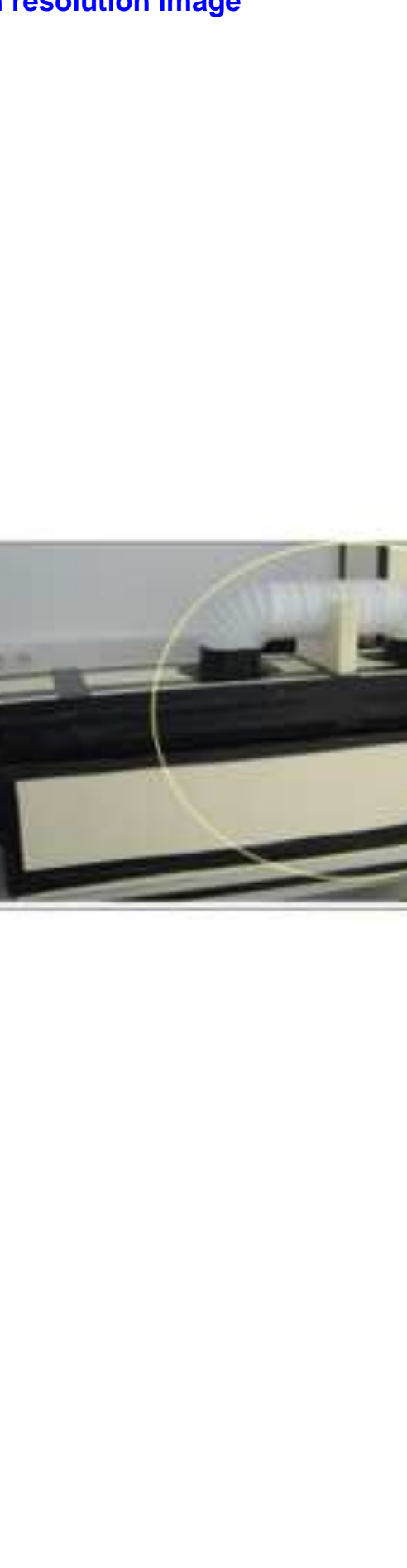

(2)

$r_{1}$




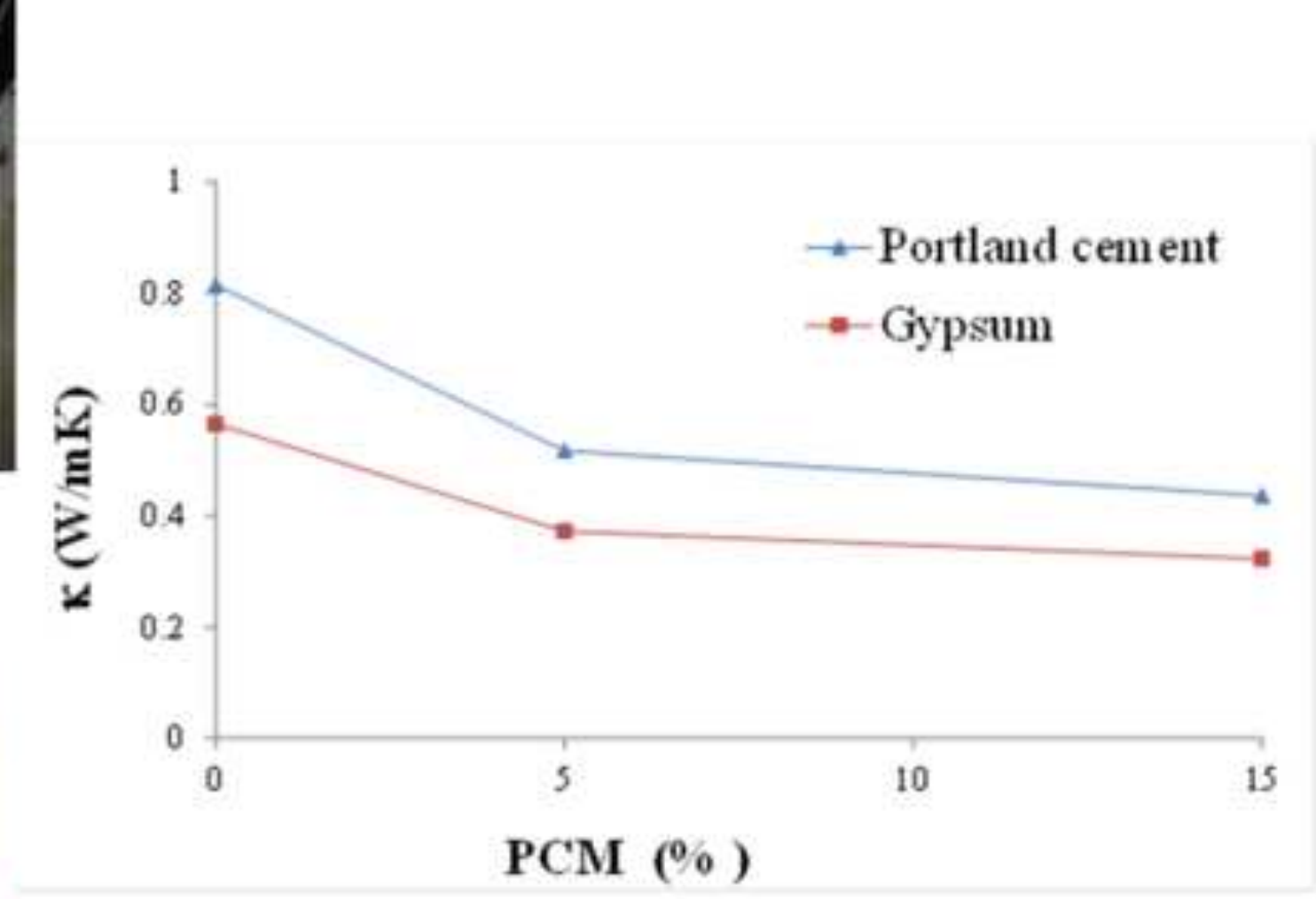

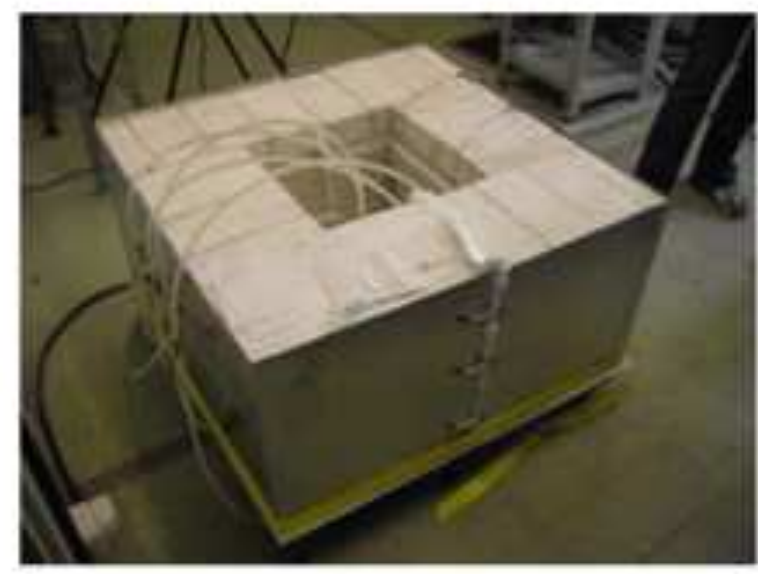

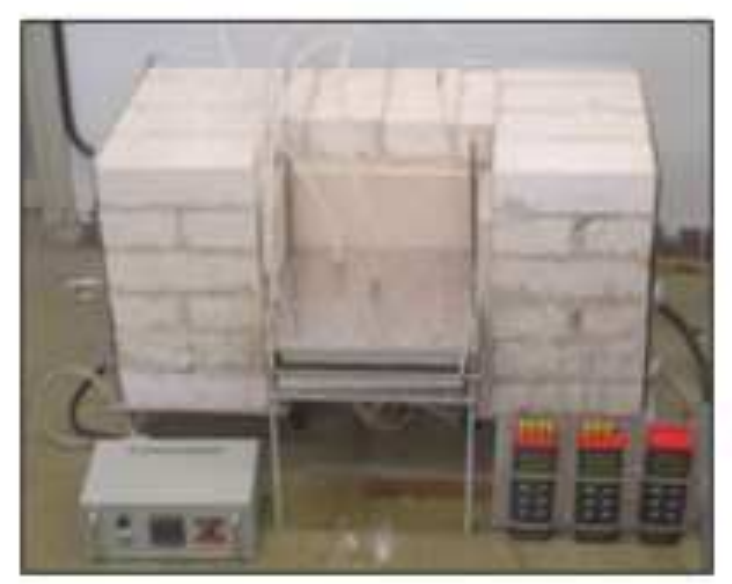

5

\footnotetext{
Fig. 37

Fig. 37
} 
Click here to download high resolution image

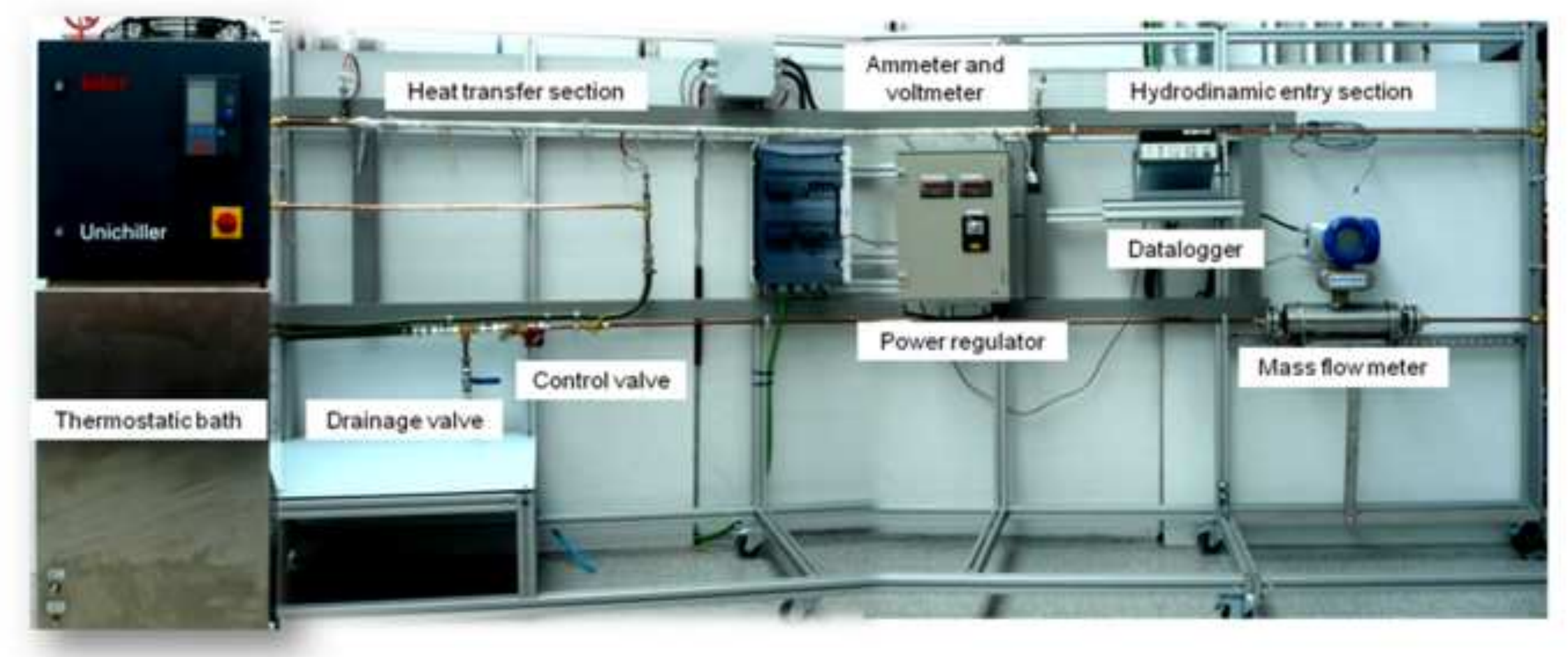

Fig. 38 


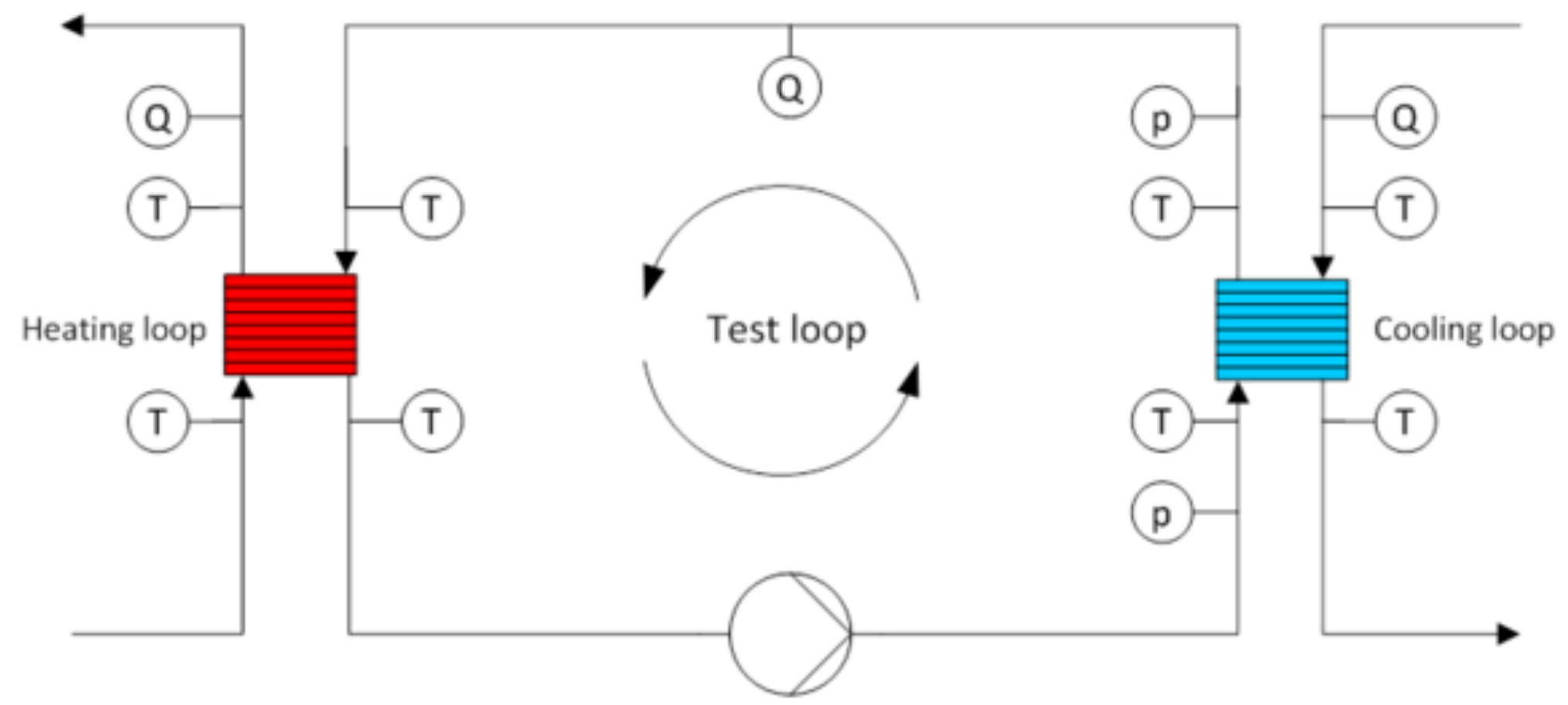

Fig. 39 
Table 1. Substances used as standards.

\begin{tabular}{|c|c|c|}
\hline Substances & Properties & Reference \\
\hline $\begin{array}{l}\text { Standard oil S60 from Canon } \\
\text { Instruments Company }\end{array}$ & viscosity & \\
\hline Octadecane & $\begin{array}{l}\text { h-T curve } \\
\mathrm{cp}_{\text {solid }} \\
\mathrm{cp}_{\text {liquid }}\end{array}$ & $\begin{array}{l}\text { COST TU0802 and IEA } \\
\text { Task 42-Annex } 24 \text { WG3 Test } \\
\text { and Characterization (RRT) } \\
\text { [9] }\end{array}$ \\
\hline Water & $\begin{array}{l}\text { h-T curve } \\
\mathrm{cp}_{\text {solid }} \\
\mathrm{cp}_{\text {liquid }}\end{array}$ & \multirow[t]{4}{*}{$\begin{array}{l}\text { ZAE-Bayern (Germany) and } \\
\text { University of Zaragoza } \\
\text { (Spain) }[10]\end{array}$} \\
\hline Gallium & $\begin{array}{l}\text { h-T curve } \\
\mathrm{cp}_{\text {solid }} \\
\mathrm{cp}_{\text {liquid }}\end{array}$ & \\
\hline Hexadecane & $\begin{array}{l}\text { h-T curve } \\
\mathrm{cp}_{\text {solid }} \\
\mathrm{cp}_{\text {liquid }}\end{array}$ & \\
\hline RT27 & $\begin{array}{l}\text { h-T curve } \\
\mathrm{cp}_{\text {solid }} \\
\mathrm{cp}_{\text {liquid }}\end{array}$ & \\
\hline
\end{tabular}

